VARGAS, Tatiana; PERIN, Andrea, "La "vidente" imputación imprudente.

Peligrosidad de la conducta y consciencia del riesgo en la definición del dolo y la

imprudencia"

Polít. Crim. Vol. 15, № 29 (Julio 2020), Art. 5, pp. 111-140

[http://politcrim.com/wp-content/uploads/2020/05/Vol15N29A5.pdf]

\title{
La "vidente" imputación imprudente. \\ Peligrosidad de la conducta y consciencia del riesgo en la definición del dolo y la imprudencia*
}

\section{The "conscious" negligent imputation. Degree of danger and awareness of risk in the definition of negligence and intent}

Tatiana Vargas Pinto

Doctora en Derecho. Profesora de Derecho Penal, Facultad de Derecho, Universidad de los

Andes (Santiago, Chile)

tatianavp@uandes.cl

Andrea Perin

Doctor en Derecho. Profesor Investigador, Facultad de Derecho, Universidad Andrés Bello

(Santiago, Chile)

andrea.perin@unab.cl

\section{Resumen}

El trabajo ofrece una reflexión en torno al elemento subjetivo de la imprudencia y la delimitación entre ésta y el dolo. Se cuestionan las doctrinas que, en ambos planos, niegan la relevancia de consideraciones subjetivas y adoptan concepciones normativas motivadas por el rechazo a las posturas "psicologizantes". Los autores argumentan el carácter doloso de aquellos supuestos que suponen conocer o asumir el hecho típico como consecuencia prácticamente segura de la conducta (dolo directo) o, al menos, con una alta probabilidad, de modo que suponga prever un peligro concreto (dolo eventual). En cambio, las conductas imprudentes se refieren a una peligrosidad (ex ante) de menor entidad y a riesgos menos irrazonables: el agente solo alcanza a considerar un peligro general, representándose un riesgo abstracto de realización del hecho típico. No obstante, puede haber imprudencia penalmente relevante, aún sin representación actual del hecho típico, cuando se adopte un comportamiento cuya peligrosidad no puede desconocerse, justificándose de este modo la imputación de un "deber de previsión".

Palabras clave: imprudencia inconsciente, imprudencia vidente, dolo, mens rea, conocimiento.

\section{Abstract}

This paper deals with the subjective element of criminal negligence and the conceptual distinction between negligence, or recklessness, and intention, as different mens rea states.

\footnotetext{
${ }^{*}$ El trabajo se desarrolla en el marco de los proyectos Fondecyt Regular № 1151103 y Fondecyt Iniciación No 11170924.
} 


\section{VARGAS, Tatiana; PERIN, Andrea, "La "vidente" imputación imprudente. Peligrosidad de la conducta y consciencia del riesgo en la definición del dolo y la imprudencia".}

The authors criticize the legal theories that deny the relevance of subjective considerations while adopting normative conceptions motivated by psychologizing objections. They argue that intention requires assuming the realization of the typical event as a practically certain consequence (direct intent) or, at least, with a high probability, so that it implies foresee a specific danger (eventual intent). On the other hand, negligent harmful conducts are dangers of lesser importance (ex-ante), or less unreasonable risks: the agent is conscious of a general danger, being able to foresee an abstract risk of realization of the typical harmful event. However, there may be criminally relevant negligence, even without actual foresight, when adopting a behavior whose danger cannot be ignored, thus justifying the imputation of a "duty of foresight".

Keywords: pure negligence, recklessness, intention, mens rea, knowledge.

\section{Introducción. El problema de la condición ciega}

Las consideraciones subjetivas encierran múltiples dificultades y objeciones, desde la complejidad probatoria hasta la indebida injerencia en la mente o psique del agente. ${ }^{1} \mathrm{Se}$ indagará aquí específicamente sobre este último asunto en el marco conceptual de la imprudencia, cuya atribución no requiere el conocimiento directo o más o menos cierto de la realización del resultado lesivo típico. ${ }^{2}$ En efecto, mientras que el dolo suele reflejar la imputación de conocimiento real o efectivo, la imprudencia consiste básicamente, al menos en su forma inconsciente, en la atribución de conocimiento debido o exigible; el conocimiento que permite considerar objetivamente previsible el resultado acaecido.

El reconocimiento de aspectos subjetivos se complica precisamente cuando el conocimiento en el que se basa el juicio de imputación falta. Sigue siendo objeto de debate si se acepta la consciencia de la posible realización del hecho típico como elemento decisivo. En efecto, la consciencia (o representación efectiva) de riesgo aparece como requisito común para la culpa o imprudencia consciente y el dolo eventual. En contraposición a las dificultades que encierra todo el ámbito subjetivo, ${ }^{3}$ la conducta no se define en términos puramente

\footnotetext{
${ }^{1}$ Así han proliferado tesis más "objetivas" del dolo como conocimiento desprovisto de voluntad, como las planteadas por Jakobs o Puppe, aunque no dejan del todo consideraciones subjetivas. JAKOBS (1997), pp. 313, 315 y 321, admite que las consecuencias dolosas son aceptables. El problema parece presentarse en la culpa o imprudencia, donde la aceptabilidad "permanece abierta"; es incierta, pero existiría a pesar de limitar la imprudencia a casos de desconocimiento del tipo (sí cognoscible). A partir de la imposibilidad de establecer "datos psíquicos" han emergido tesis más normativas del dolo como la de RAGUÉS I VALLÈS (1999), p. 324 , que atiende a la valoración social y a la comunicación normativa, pero igualmente habla de "negación consciente de una concreta norma penal".

2 Ciertamente, quien actúa imprudentemente no busca el resultado típico producido. Sin embargo, este desconocimiento proviene del conocimiento de una conducta distinta de aquella dirigida a la producción del resultado. Se parte de la base de que conducta y efectos se distinguen, pero están relacionados como antecedente y consecuente. Esto conlleva el rechazo de las tesis que excluyen toda conexión con el resultado por su desconocimiento y repercute en la construcción subjetiva de la imprudencia, según se verá.

3 SOTOMAYOR (2016), pp. 694-698, muestra que una noción “psicológica-descriptiva pura” del dolo no solo es inadecuada jurídico-penalmente, sino que es insostenible desde la práctica judicial. Aclara el autor que la dificultad para probar hechos internos, por inferencia de los externos, no ha de llevar a suprimir la realidad por la valoración. Sin prueba nada hay que valorar y todo queda a discreción del juez. Una crítica a la
} 


\section{Polít. Crim. Vol. 15, № 29 (Julio 2020), Art. 5, pp. 111-140 [http://politcrim.com/wp-content/uploads/2020/05/Vol15N29A5.pdf]}

objetivos. No suele aceptarse, ni siquiera como base de imputación, la idea causalista de conducta como movimiento corporal que produce un resultado típico. ${ }^{4}$ Tal noción decae no solo frente a los delitos de mera actividad y a los de omisión, ${ }^{5}$ por falta de resultado o de movimiento externo respectivamente; la concepción causal también se opone a elementos básicos del comportamiento humano, dirigido por el agente y no construido desde su sola exteriorización. Así se evidencia frente a la vigencia y cumplimiento de las normas jurídicas que se dirigen a comportamientos que pueden guiarse y no a meros resultados ${ }^{6}$; sin perjuicio de la vinculación entre ambos.

Esta consideración es especialmente relevante en contextos, como el sector médico, en los que la entidad de los riesgos y la frecuencia de consecuencias lesivas pueden llevar a imputar resultados sin requerir advertencias subjetivas por los agentes que intervienen. La situación se agrava cuando se amplía la noción de imprudencia, como ocurre con condenas basadas en la falta de exámenes requeridos aun si el paciente no presenta características de riesgo que determinan la práctica de tales exámenes para conocer el peligro efectivo.

El contexto médico permite reflexionar acerca de casos límites. Pero la dificultad de determinación "subjetiva" de la culpa o imprudencia exige mayor precisión del problema general. Por ello, se examinarán concepciones normativas-objetivas para aproximarse a la delimitación de la imprudencia; se indagará en formas particulares de "conocimiento" (consciencia de peligrosidad y de peligro) y se culminará con la propuesta que aquí se defiende, que se opone al olvido de consideraciones subjetivas. La tesis objeta el enfrentamiento tajante entre apreciaciones normativas y fácticas. Las concepciones extremas suponen visiones parciales de un problema complejo, que suelen llevar a soluciones binarias en pro de un aspecto u otro.

Una concepción causal pura supone admitir un proceder ciego, un comportamiento humano mecánico que no puede ser controlado por el agente. Es cuestionable incluso hablar de "agente" respecto de un "movimiento" cuya dirección no asume, ni advierte. Semejante

inferencia por un dualismo clásico (extremo), que separa mente y cuerpo en DUFF (1990), pp. 117-135. Advierte la conexión entre ambos, desde que incluso el actus reus supone un acto voluntario, aunque luego se requiera discernir sus ulteriores intenciones, relevantes para adscribir una agencia racional a su agente (mens rea), al examinar la relación entre acción y su contexto. Se trata de identificar patrones y direcciones de la conducta en su contexto.

${ }^{4}$ Semejante concepción mecánica explica la reacción de Welzel con tesis que rescatan la finalidad de la conducta "vidente": WELZEL (1997), pp. 53-54. Sin embargo, esta concepción luego se objeta especialmente al no poder explicar la imprudencia, por falta de dirección hacia el resultado.

${ }^{5}$ Suele rechazarse la existencia de un vínculo causal en las omisiones por no existir antecedente y se habla de una causalidad hipotética. Puede cuestionarse este usual rechazo al advertir un real antecedente en dejar que los cursos causales sigan su curso. Aun así, las conductas omisivas no se revelan como meros aconteceres.

${ }^{6}$ Especialmente a raíz de conductas tentadas, ver MAÑALICH (2017), pp. 465-474.

${ }^{7}$ Así, la SCS de 2 de julio de 1998, Rol: 396-1998, reacciona contra la condena que determina negligencia cuando no existía pruebas sobre factores de riesgo que exigieran la práctica de exámenes omitidos. Aquí no solo falta conocimiento del peligro para el paciente por la falta de exámenes, sino que ni siquiera hay consciencia de una situación de riesgo general que demande realizar dichos exámenes. En el caso, no había antecedentes de tuberculosis, tabaquismo y alcoholismo necesarios para entender que no se practicaron todos los exámenes que determinarían la negligencia. La Corte Suprema además declara que "también una reacción individual, no previsible, a las drogas anestésicas, pudieron ocasionar el paro cardio respiratorio". 


\section{VARGAS, Tatiana; PERIN, Andrea, "La "vidente" imputación imprudente. Peligrosidad de la conducta y consciencia del riesgo en la definición del dolo y la imprudencia".}

forma de acción, sin conocimiento, es generalmente rechazada por irreal ${ }^{8}$. Otro asunto es distinguir la relevancia de la subjetividad según el contexto de la conducta, su sentido, y respecto de qué pauta de valoración. Algo de subjetivo ya hay en la conducta, como base de atribución, que queda fuera de la culpabilidad como juicio de reproche e imputación personal.

Es curioso advertir que el rechazo general a conductas ciegas no se condice con el reconocimiento subjetivo en el comportamiento. En la teoría jurídico-penal actual de corte normativista, la consideración de la mente del agente cobra cada vez menor importancia, hasta rechazarse del todo. En cambio, en la tradición de Common Law, la mens rea (guilty "state of mind") ha representado generalmente uno de los pilares fundamentales, junto con el actus reus ${ }^{9}$, normalmente en términos de intención (intention) y consciencia de riesgo (recklessness); mientras que la inclusión de la imprudencia (negligence) ha sido objeto de mayores críticas precisamente por su carácter inconsciente. ${ }^{10}$

Desde una perspectiva diacrónica y comparativa, se puede afirmar que la idea de mens rea mantiene, al menos generalmente, aquellas connotaciones psicológicas que fueron características también del "elemento subjetivo" de la teoría del delito europea-continental decimonónica clásica. ${ }^{11}$ Aquella sistemática bipartita se mantuvo así hasta los cambios de paradigma que supusieron, por un lado, el pasaje desde la concepción psicológica a la concepción normativa de la culpabilidad a partir del principio de "inexigibilidad"12 y, por otro, la asunción de la sistemática post-welzeliana, que llevó la imprudencia —así como también el dolo - a integrar un elemento del tipo (como tipo-subjetivo). En cambio, en las

\footnotetext{
${ }^{8}$ BUSTOS (1995), pp. 40-41, critica la discusión entre tesis individualizadores y generalizadoras por tomar un sujeto irreal, pues, según defiende, siempre se ha de considerar al sujeto concreto en la situación determinada y su participación requiere conocimiento.

${ }^{9}$ La máxima actus non facit reum nisi mens sit rea explica que un acto no hace culpable a una persona a menos que su "mente" también sea culpable. Ver DUFF (1990), pp. 7-9, 116 y ss. Sobre ambos pilares, además, SIMESTER et al. (2016), p. 71 y ss., p. 133 y ss.

A propósito de la tradición considerada, cabe aclarar que, en estricto rigor y según señala OXMAN (2013), pp. 139-194, p.140, nota 2, en la doctrina norteamericana la expresión Common Law se refiere a "un conjunto de costumbres jurídicas imperantes en la tradición angloamericana que encuentra su apoyo en normas de fundamento común y prácticas sociales que han servido para la evolución de las decisiones judiciales" (así citando a SCHAMALLEGER (2006), p. 20). No obstante, esa expresión se emplea aquí en el sentido más amplio de "cultura" o "familia" jurídica que identifica el conjunto de "experiencias que históricamente proceden del derecho inglés medieval y moderno (...)": así, GAMBARO (2008), p. 31 (trad. nuestra).

${ }^{10}$ Paradigmática, en este sentido, la crítica de HALL (1963), pp. 632-644, al Model Penal Code, por la inclusión de la imprudencia entre las formas de culpabilidad (MPC § 2.02(2) (d)). Opuesta a la concepción voluntarista, esencialmente hegeliana, de Jerome Hall (p. 636), la postura cognitivista defendida por HART (1968), pp. 136 y ss., quien admite la imprudencia sin representación; de forma semejante, FLETCHER (1971), pp. 401-438.

${ }^{11}$ Ver CADOPPI (1993), pp. 618-652, pp. 621 y ss.; no obstante se tenga que distinguir entre concepciones "unitarias" de la mens rea y planteamientos que defienden concepciones diferenciadas de "mentes reae": así, SAYRE (1932), pp. 974-1026, pp. 1004 y ss, p. 1026. Sin perjuicio de lo anterior, cabe destacar que también en este contexto las distintas categorías dogmáticas de imputación subjetiva han tendido a objetivarse a través de la creación de múltiples categorías. Para una perspectiva general, OXMAN (2014), pp. 341-356; además de las obras citadas en la nota 16 de este trabajo.

${ }^{12}$ Sobre esta evolución, entre otros: FORNASARI (1990), passim; DONNA (2002), pp. 11-50.
} 
experiencias de Common Law se advierte una mayor inclinación a separar la subjetividad, respondiente a la noción de mens rea, como un elemento que se manifiesta externamente a través del actus reus. ${ }^{13}$ También por ello, la negligencia (negligence) ha sido muy criticada $^{14}$; precisamente por faltar cualquier advertencia; esto es, por ser inconsciente. ${ }^{15}$

La noción de imprudencia inconsciente supone un desconocimiento que resulta cuestionable. Cabe preguntarse si también esta clase de responsabilidad debería exigir algún conocimiento, aunque éste no llegue a identificarse con la representación efectiva del resultado. La distinción entre recklessness y negligence se plantea, en ocasiones, precisamente a partir de la consciencia del riesgo. ${ }^{16} \mathrm{Y}$ esto refleja la importancia de distinguir el objeto del conocimiento, su modalidad y grados, ${ }^{17}$ en cuanto se defienda la oportunidad de evitar que la imprudencia inconsciente se base solamente en la valoración objetiva (generalizadora) que se realiza acudiendo al baremo objetivo de la "persona racional y prudente"; lo que reduce el reproche a un juicio de atribución de conocimientos debidos a dicho parámetro, en cuanto se valoren exigibles al miembro típico del grupo profesional o social al que pertenece el autor del hecho. ${ }^{18}$ Se trata, en efecto, de un

${ }^{13}$ DUFF (1990), pp. 143 y ss., reacciona contra el modelo dualista al examinar la noción de indiferencia que suele concebirse en el sistema anglonorteamericano a partir de la exigencia de una subjetividad explícita como recklessness, según veremos. Desde ya se destaca que mantiene la consideración subjetiva de indiferencia, solo que no como requisito explícito añadido y que se deduce a partir del significado de la conducta, de su contexto (una "indiferencia práctica"). Confróntese, ROBINSON (1993), pp. 187-211, pp. 202 y ss., con especial referencia a la mens rea, y 206 y ss.

${ }^{14}$ Véase, por ejemplo, el Criminal Damage Act de 1971, Section 1. De todos modos, cabe observar que los sistemas penales suelen limitar la responsabilidad imprudente a las conductas que afectan a bienes jurídicos primarios, esencialmente la vida y la salud (o integridad psico-física), aunque a veces se extienda a los delitos económicos. Se trata de un aspecto político-criminal objeto de cierto consenso en la doctrina comparada: ver, por ejemplo, STARK (2016), p. 272, quien, a la vida y la salud, añade también la autonomía (o libertad) sexual.

${ }^{15}$ Por ello, se considera excepcionalmente en casos graves - gross negligence, imprudencia grave- de muertes (manslaughter), no como un elemento mental definido, sino como una conducta extremada y/o irrazonablemente descuidada. Así, por ejemplo, LOVELESS (2016), pp. 91, 93, 102, 120-146.

${ }^{16}$ En este sentido, BRADY (1996), pp. 325-335, pp. 325 y ss.; WINSLADE (1972), p. 32. Ver, no obstante, SIMESTER et al. (2016) pp. 150 y ss., 159 y ss., sobre las versiones objetivas, basadas en la categoría de riesgo (glaring, patente), y subjetivas, centradas en la representación efectiva del mismo (actual foresight), de la categoría recklessness. Al respecto, confróntese, también STARK (2016), pp. 219 y ss.; y, en este medio, OXMAN (2013), pp. 168 y ss., 173 y ss.

17 Veremos especialmente la tesis de BRADY (1980), pp. 383-392, que no solo distingue grados de advertencia de riesgo — con distinción de la representación cierta o "casi cierta" del resultado_-, sino que también devela intersecciones entre recklessness y negligence que no dejan de perder los contornos que los definen.

${ }^{18} \mathrm{Si}$ bien algunos autores rechazan la premisa, generalmente asumida en el marco de la misma tradición, según la cual el juicio de imprudencia debería ser exclusivamente "objetivo" (recte, generalizador). Así FLETCHER (1971), p. 428, quien, conocedor de la dogmática alemana, defiende la necesidad de distinguir entre "the legality of conduct" y "the culpability of the individual". De este modo, reconocida su doble dimensión (típica y culpable, diríamos nosotros), la imprudencia sería una forma legítima de mens rea. Sobre el papel de la "ciencia normativa" o "reguladora" (regulatory science) en la construcción normativa del baremo generalizador, y, en particular, en la atribución al mismo parámetro de los conocimientos debidos, PERIN (2019), pp. 211-225, pp. 213-215, y 220, nota 11, también para referencias ulteriores. 
VARGAS, Tatiana; PERIN, Andrea, "La "vidente" imputación imprudente. Peligrosidad de la conducta y consciencia del riesgo en la definición del dolo y la imprudencia".

parámetro de medición que incide en el juicio de imputación de responsabilidad frente a la conducta como objeto enjuiciado. ${ }^{19}$

En el contexto continental se advierte una tendencia objetivista respecto de los llamados elementos subjetivos, que incluso alcanza al dolo. ${ }^{20}$ En este sentido, los juicios de atribución prescindirían de la prueba de elementos subjetivos asumidos como condiciones psíquicas. Sin embargo, la asunción de concepciones normativas motivadas por el rechazo a las posturas "psicologizantes" puede llevar a confundir la valoración con el objeto juzgado. $^{21}$ Solo procede hablar de dolo e imprudencia luego de una determinación normativa, qué duda cabe; $;^{22}$ pero la definición del dolo como mera "atribución" lleva consigo un riesgo evidente de extensión punitiva. Por ello, no se niega aquí la necesidad de realizar consideraciones normativas (esto es, valorativas), que son propias de determinaciones jurídicas; simplemente se rechazan tesis parciales que desvirtúan los presupuestos de imputación o los conciben como hechos ajenos que concurren como un elemento fáctico más.

El examen que sigue parte de la base de tipos penales que describen conductas y de normas que determinan comportamientos. Este reconocimiento guía el cuestionamiento de doctrinas que niegan consideraciones subjetivas, particularmente en la definición de la imprudencia, ya se califique de consciente o inconsciente.

\section{Develo de las concepciones normativas-objetivas de dolo e imprudencia}

${ }^{19}$ En este sentido es interesante la base común que revela OXMAN (2016), pp. 23-39, la norma penal integrada por la descripción de conductas y la asignación de consecuencias jurídicas. Se destaca en el sistema angloamericano la distinción entre la contradicción de las normas (de conducta), que ex ante establecen lo correcto, y la habilitación ex post de persecución penal por la posibilidad de adjudicación de responsabilidad penal, aunque la referencia a "normas jurídicas de imputación" parece unir ambos planos.

${ }^{20}$ Una muestra del proceso de normativización en CANCIO (2010), p. 158, que parte con la imprudencia y sigue con el dolo, primero con la voluntad y luego derechamente con el conocimiento. Semejantes concepciones "monistas" resultarían en todo caso incompatibles con algunos ordenamientos positivos de procedencia "clásica", como por ejemplo el italiano, donde el art. 43 del Código Penal define doloso el delito cuando el resultado es "preveduto e voluto" como consecuencia de la acción u omisión, y prevé la "colpa con previsione dell'evento" como forma agravada de imprudencia (art. 61, núm. 3, Código Penal). La misma incompatibilidad subsistiría respecto al sistema español, deduciéndose esta conclusión de la exigencia de "ambos componentes de la acción humana", conocimiento y voluntad, "en diversos preceptos del CP que regulan el error sobre el tipo, la tentativa y otros elementos subjetivos que no pertenecen al dolo, pero se incorporan asimismo a la parte subjetiva del tipo (tipo subjetivo)": ROMEO CASABONA (2009), pp. 12 y ss., 55-59. Además, en la opinión del autor, las posiciones monistas no contribuyen a lograr un mayor nivel de seguridad jurídica; por el contrario, "una perspectiva psicológico-individual contribuye de forma decisiva al aseguramiento de principios garantistas, materiales y formales, frenando el excesivo arbitrio de los tribunales en la apreciación de los elementos subjetivos". Manifiesta sus preocupaciones ante la normativización y objetivización de todo elemento subjetivo también DONINI (2014), pp. 70-127, pp. 82 y ss.

21 Confróntese. ROXIN (1997), p. 417, distingue "plan del autor" de "valoración objetiva", aunque la integración de ambas ideas en la definición de dolo lleva a identificar dolo con valoración; ROXIN (2007), pp. 171 y ss.

${ }^{22}$ Confróntese, la separación entre hecho (subjetivo) y sentido jurídico, que destaca el doble estatuto del dolo como una realidad luego valorada, planteada por PÉREZ (2017), pp. 355-359. 


\section{Polít. Crim. Vol. 15, № 29 (Julio 2020), Art. 5, pp. 111-140 [http://politcrim.com/wp-content/uploads/2020/05/Vol15N29A5.pdf]}

Los problemas subjetivos aparecen en las conductas imprudentes por falta de conocimiento más o menos cierto de la realización del resultado requerido por el tipo penal, a diferencia del dolo. ${ }^{23}$ La definición de la imprudencia como mera infracción del deber de cuidado supone asumir una noción normativa que prescinde de aspectos subjetivos. Y, como ya destacamos, esta determinación normativa se ha reforzado en el último tiempo también respecto del dolo. ${ }^{24}$

No obstante, la imprudencia puede admitir también una consciencia de riesgo; esto es, la previsión de la posible realización del tipo penal (en particular, del elemento dado por el resultado lesivo). Este conocimiento, en cuanto se entienda como calidad subjetiva referida a la peligrosidad de la conducta — es decir, al riesgo generado por la ejecución de ésta—, ${ }^{25}$ puede sin embargo generar confusión con el dolo eventual, ${ }^{26}$ caracterizado también por la representación de la realización del hecho típico como posible. Esta previsión, o representación, sería en efecto un requisito común en ambas formas subjetivas, explicándose así tanto los esfuerzos por distinguirlas, como las tesis que las identifican, ya a modo de dolo ${ }^{27}$ o de imprudencia. ${ }^{28}$

El problema de la definición subjetiva de la imprudencia inconsciente resulta así aun más relevante. Esta clase de responsabilidad prescindiría del conocimiento del agente, centrándose su atribución en el descuido externo, en la infracción de una norma objetiva de cuidado. Aquí emerge la definición normativa fuera de consideraciones subjetivas y, con

\footnotetext{
${ }^{23}$ Especialmente problemática fue la explicación de la imprudencia desde la perspectiva finalista. La finalidad de la acción requerida como asunción ontológica no pudo encontrar un correlativo normativo satisfactorio en la imprudencia desprovista de cualquier elemento psicológico y dirección. La noción de "finalidad potencial" (WELZEL (1951), p. 43) no permitió evitar que - por paradójico que parezca - también WELZEL (1961), pp. 7 y ss., aceptara una concepción normativa de la imprudencia, basada como tal en la inobservancia del deber objetivo de cuidado (mientras que, como es sabido, otra parte de esta corriente ha defendido la necesidad de una consciencia de riesgo para poder imputar la imprudencia inconsciente).

${ }^{24}$ PÉREZ (2012), pp. 11-49, pp. 11-13, objeta el dolo como conocimiento y voluntad. Igualmente reconoce un rol a esos elementos, aunque como datos empíricos que "pueden" ser relevantes para conformar supuestos de hecho que "realicen el dolo o la imprudencia" y nada aportan al concepto. Después (p. 42), el autor niega los aspectos subjetivos. Prefiere hablar de "tipo de explicación" y "tipo de imputación" antes que de tipo objetivo y tipo subjetivo. Distinto es que la determinación del dolo haya de ser normativa al sujetarse a un juicio de valor con atención a cierta pauta, sin negar un objeto de juicio, como puede rescatarse de la explicación de RAGUÉS I VALLÈS (2012), pp. 1-12, p. 3. Quizá solo falte distinguir el plano descriptivo del normativo.

${ }^{25}$ Es probable que muchas de las confusiones sobre la clase de conocimiento provengan de la falta de distinción entre peligrosidad de la conducta y resultado de peligro, que se tomará de Hirsch.

${ }^{26}$ Un panorama en RAGUÉS I VALLÈS (2012), pp. 53 y ss. En la jurisprudencia chilena se ha seguido mayoritariamente la tesis de la voluntad, probablemente motivada por una noción general de dolo que admite conocimiento y voluntad de realización del tipo penal. Así, SCS de 13 de marzo de 2017, Rol n 2882-2017; SCS de 2 de julio de 2009, Rol n 3970-2008; SCS de 18 de noviembre de 2008, Rol n 6222-2007. Aunque también hay sentencias que acogen una distinción en el nivel de posible ejecución del tipo, si conoce su probabilidad (dolo eventual) o su sola posibilidad (culpa consciente), aunque repercuta en su aceptación, como SCA de La Serena de 19 de abril de 2011, Rol n 56-2011.

${ }^{27}$ JAKOBS (1997), pp. 315, 316, 321 y ss., define dolo por el conocimiento del riesgo de realización del tipo, que incluye la búsqueda del tipo por sí mismo o por sus consecuencias principales, como la advertencia de consecuencias secundarias.

${ }^{28}$ BUSTOS (2007), pp. 612-616.
} 
VARGAS, Tatiana; PERIN, Andrea, "La "vidente" imputación imprudente. Peligrosidad de la conducta y consciencia del riesgo en la definición del dolo y la imprudencia".

ella, la cuestión sobre si puede surgir e imputarse un deber de precaución frente a supuestos que se desconocen o no han sido objeto de representación actual.

Algunos autores condicionan la imprudencia, como forma de imputación extraordinaria, a la apreciación de una conducta consciente anterior ${ }^{29}$ En este sentido, se puede afirmar que, sancionando la culpa inconsciente, se castiga una "culpa anterior", el hecho de no haber sido cuidadoso el autor a la hora de cumplir con el "deber de conocer". ${ }^{30}$ El objetivo de esta construcción es evitar que la previsibilidad, como exigencia mínima, ${ }^{31}$ se entienda como mera posibilidad de conocer el riesgo de realización de un resultado (más o menos hic et nunc) respondiente a la categoría de resultado considerada por el tipo penal (muerte, lesiones, daños, etc.). De otra forma no se podría distinguir o apreciar un estado de consciencia referible a la peligrosidad de la conducta o a propiedades de riesgo de verificación del tipo.

${ }^{29}$ Esta noción es compatible con la exclusión de todo conocimiento actual de la realización del tipo penal, suponiendo, sin embargo, la existencia de un hecho anterior cuya valoración se realizaría acudiendo a las reglas del error vencible. Así, SÁNCHEZ-OSTIZ (2008), pp. 46, 458 y ss., aclarándose en qué sentido la imputación extraordinaria es el ámbito propio de la imprudencia. La actio libera in causa y la omissio libera in causa justifican la "incumbencia" que posibilita la imputación del deber de cuidado. Confróntese, en nuestro medio, MAÑALICH (2015), pp. 14-18, 21, quien también refiere el dolo a la imputación ordinaria y la imprudencia a una imputación extraordinaria; y el propio SÁNCHEZ-OSTIZ (2017), pp. 1214-1215, 1221 y ss. Por "incumbencia" se entiende una condición anterior al deber para que la norma sea efectiva. Se trataría de un imperativo hipotético que incorpora una condición: si eres destinatario de la norma, preocúpate por conocer el concreto deber y circunstancias del caso, así como mantenerte en disposición de poder cumplirlo. Esta incumbencia mantendría la imputación del hecho. El deber de cuidado entraría después de la imputatio facti, en la imputatio iuris, para valorar los efectos del precepto del delito imprudente. Respecto del imperativo hipotético para la imputación extraordinaria del hecho, aunque se distinga "norma" y "deber" concreto, cabe preguntarse cómo se puede ser destinatario de una norma sin un conocimiento mínimo actual. Solo podría ser un destinario general, en cuanto se dirige a todos, pero no cabe imputar un hecho (racional) aún. Quizá así tiene más sentido la concreción del destinatario, aunque a nivel de deber, como el mismo SÁNCHE-OSTIZ (2017), p. 1215, revela: la norma per se no es apta para la acción hasta que el destinatario conoce su contenido y lo aplica. MAÑALICH (2017), p. 470, habla de exhibir estatus de norma como "razón 'objetivamente existente"'. Su fuerza motivacional no está asegurada per se, sino que depende de que esa norma sea "subjetivamente reconocida" por su destinatario. Sobre la exigencia de una "advertencia anterior" justificante la imputación de responsabilidad por conductas y consecuencias sin consciencia o representación actual, confróntese, ZIMMERMAN (1986), pp. 199-218, pp. 205 y ss., según el cual el "control requisite for moral responsibility may be, and often is, anchored in the earlier advertence".

${ }^{30}$ En estos términos, CORNACCHIA (2004), p. 562. Se trata entonces de una "culpa por asunción", que remite a una "falta" anterior a la conducta ofensiva. Sobre dicha culpa (y reprochabilidad) "por ignorancia", pero especialmente desde la perspectiva de la responsabilidad moral (antes que jurídica y jurídico-penal), SMITH (1983), pp. 543-571, quien nos propone una mirada crítica acerca de las tesis subyacentes a esta discusión: la aceptación de la "culpa por ignorancia" basada en el deber de conocer (desde una perspectiva, podríamos decir, más "normativista"); la exclusión de la responsabilidad del individuo justificada precisamente por la ausencia de conocimiento (doctrina "liberal"); posturas y argumentos intermedios. Todo esto, como destaca claramente Smith, nos remite inevitablemente a las cuestiones filosóficas acerca de la relación (¿Posible? ¿Necesaria?) entre responsabilidad moral y jurídica, y sobre el papel del azar en la imputación de responsabilidad por consecuencias en cierta medida inconscientes o más allá del control o dominio del autor del hecho (moral luck). Confróntese, obras y autores citados en la nota anterior.

En cuanto a la praxis judicial, sobre la mayor reprochabilidad de la "ignorancia inexcusable" (sub-especie de culpa in eligendo) respecto a los errores ejecutivos, en la jurisprudencia comparada en materia de responsabilidad médica, PERIN (2018), pp. 858-903, pp. 882 y ss., 884 y ss.

${ }^{31}$ Para una visión general, VARGAS (2017), pp. 360-367. 
La debilidad de nociones de previsibilidad, y aun de cognoscibilidad, se esconde tras la delimitación unitaria de la imprudencia como infracción de un deber objetivo de cuidado. El vuelco hacia concepciones objetivas-normativas es más evidente en esta clase de imprudencia "inconsciente". De hecho, faltas de representación se han equiparado al dolo a modo de ignorancia o ceguera "deliberada", al valorar el nivel de (ir)racionalidad de la falta de conocimiento. Ragués i Vallès, ${ }^{32}$ por ejemplo, explica que la falta de representación puede reclamar igual necesidad de pena que supuestos de dolo eventual al expresar "un grado de indiferencia equiparable". El problema de amplitud es serio y ya no se presenta solo frente al supuesto más obvio de la imprudencia inconsciente. La equiparación se sostiene en términos funcionales, una intensidad comunicativa de la conducta equivalente, básicamente desde propuestas de Jakobs.

En principio, Jakobs $^{33}$ se refiere al déficit de fidelidad al Derecho que supone la culpabilidad y, en este contexto, afirma que la ignorancia evitable no descarga de responsabilidad al agente. Se refiere el autor al desconocimiento de la (i)licitud, de la norma concreta, que no aportaría ningún dato relevante para la decisión, pero tampoco sería superfluo. Funda la culpabilidad en una actuación con indiferencia hacia del Derecho, pues el agente, sin tener datos para determinarse, igualmente actúa. El problema es que tales consideraciones también se extienden al conocimiento del hecho típico, con una riesgosa equivalencia. ${ }^{34}$ Falta tener en cuenta que una indiferencia en términos de "actuar igualmente" supone en realidad un "pero" o "a pesar de", un obstáculo que es conocido y que es indiferente para la voluntad. ¿Por qué Jakobs considera el determinarse "igualmente" a actuar si entiende que el agente nada advierte, si hay realmente ignorancia?

Brady $^{35}$ muestra que el recurso a la indiferencia se sostiene para separarse de la noción de conducta "intencional", pero aclara que la indiferencia se explica ante una conducta

${ }^{32}$ RAGUÉS I VALLÈS (2012) pp. 182 y 183.

${ }^{33}$ JAKOBS (2004), p. 346.

${ }^{34}$ Sobre las consecuencias de una equiparación en el régimen de responsabilidad, BRADY (1980), pp. 384386, 389, quien muestra que la falta de delimitación entre negligence y recklessness - o su equiparación - en el sistema anglonorteamericano puede llevar a formas de responsabilidad objetiva. El autor se centra también en la confusión entre recklessness e intention (BRADY (19080), pp. 393 y ss.), que en nuestra tradición se torna relevante a propósito del umbral entre el dolo eventual y el dolo directo, especialmente cuando el primero se confunde con formas de culpa o imprudencia.

35 BRADY (1980), pp. 386-390. DUFF (1990), pp. 141 y 142, muestra la indiferencia como caso de recklessness cuando el agente injustificadamente hace algo que sabe dañará a otro. Sin embargo, precisa el autor que jurídico-penalmente para que la conducta sea reckless el agente no puede ser indiferente. Él ha de preocuparse, lamentar asumir el riesgo y esperar que no se produzca daño. El problema es que también considera una clase de indiferencia aquella que no requiere advertencia actual del riesgo (DUFF (1990) pp. 143, 149 y ss.). Habla de una "indiferencia práctica" (practical indifference) que no solo incluiría elegir tomar un riesgo no razonable, sino también el fallar en advertir un riesgo obvio o actuar bajo la creencia no razonable de que no existe riesgo. La pregunta es cuándo falla en advertir o hay creencia no razonable. Pareciera no haber conocimiento, pero un riesgo obvio o el criterio de no razonabilidad de la creencia no tienen sentido sin una conducta voluntaria, que advierta algo. Duff habla de una indiferencia desalmada o insensible (callous indifference), que difícilmente se entiende sin una conducta peligrosa conocida. En realidad, él reacciona contra la exigencia de pensamientos explícitos, con una visión dualista de indiferencia (estado mental presente) que critica. Veremos que admite un conocimiento actual manifestado al actuar, según contexto y efectos posibles. Aclara que la indiferencia tiene que ver con el significado de la conducta 
VARGAS, Tatiana; PERIN, Andrea, “La “vidente” imputación imprudente. Peligrosidad de la conducta y consciencia del riesgo en la definición del dolo y la imprudencia".

peligrosa cuando el agente advierte los riesgos, aunque no se represente (totalmente) sus consecuencias; ellas "no le importan suficientemente". Incluso, se ha vinculado la indiferencia con el actuar de propósito. ${ }^{36}$ Hay un elemento de la voluntad en esta indiferencia, que puede adquirir un sentido más preciso una vez delimitadas de mejor manera las formas de conocimiento relevantes a efectos de reproche.

El desconocimiento vencible remite a la imprudencia inconsciente o sin representación. El nexo entre dicho desconocimiento y la categoría subjetiva estribaría precisamente en la evitabilidad del error, condición que se cumple si el autor podía (y debía) conocer empleando el cuidado debido. Sin embargo, si no se puede apreciar un conocimiento inicial, o básico, que permita justificar la imputación de responsabilidad por un supuesto de hecho vinculado con los elementos del tipo penal, la legitimidad de dicha exigencia resulta problemática.

El juicio sobre la evitabilidad del error y, en particular, de cierto estado de ignorancia, se puede asimilar a la valoración del desconocimiento evitable de la ilicitud. Jakobs ${ }^{37}$ alude a la previsión de una atenuante facultativa $(\S 17.2 S t G B)$ y critica la indecisión del legislador alemán al resolver este caso por una atenuante obligatoria. Esta crítica frente a respuestas distintas parece identificar ambos errores; pero Jakobs rechaza además la respuesta española única sobre la base de una atenuación obligatoria. En realidad, la legislación española distingue el error evitable sobre presupuestos del tipo, como imprudencia, del error evitable sobre la licitud. La objeción se refiere más bien a la obligatoriedad de la atenuación y no a la respuesta única. La equiparación respecto del error se mantiene. Es especialmente claro en este sentido cuando señala que la indiferencia respecto del Derecho puede "degenerar" en indiferencia sobre los hechos relevantes como elementos del tipo ${ }^{38}$.

Recientemente se han considerado indiferencias graves o sumas en el medio jurídico-penal chileno, precisamente de modo limitado y sin concreción legal aún. El Anteproyecto de Código Penal chileno de 2018 considera la "suma indiferencia" en un contexto restringido

(práctica), no con sentimientos. La crítica que le dirige WILLIAMS (1982), pp. 286-289, no se refiere a la indiferencia como advertencia de riesgos desatendidos, sino a los casos de Duff, que entiende son ejemplos de inadvertencia de riesgos. En este sentido se afirma que una persona no toma en cuenta (disregard) un riesgo si lo advierte y decide ignorarlo. La indiferencia no supondría desconocer riesgos.

${ }^{36}$ WINSLADE (1972), p. 31. También en la práctica chilena, STOP de Copiapó de 8 de diciembre de 2006, Ruc: 0510000049-2: “...los elementos característicos de la figura del dolo eventual son: a) Acción u omisión del sujeto activo. b) Posibilidad cierta de la producción de un hecho típico a consecuencia de dicha acción u omisión. c) Este hecho típico posible, no es un objetivo perseguido por el sujeto activo, pero le es totalmente indiferente, siendo acogido como una posibilidad que no rechaza, no haciendo nada por evitarla." Así también se ha considerado la falta de indiferencia para no imputar a dolo eventual, aunque sí imprudencia, STOP de Copiapó de 8 de diciembre de 2006, Ruc nº 0510000049-2.

${ }^{37}$ De hecho, cita de ejemplo un agente consumidor de drogas que procura obtener una nueva sustancia, con conocimiento de su composición, pero no de su prohibición. JAKOBS (2004), p. 346.

${ }^{38}$ JAKOBS (2004), p. 347, retoma el caso de las drogas y se refiere al desconocimiento de la composición de las sustancias; pero el desconocimiento parece radicar en la particular clase de drogas y no en su condición de drogas. Luego define el dolo en términos de culpabilidad y, en ese caso, se comprende una propuesta unitaria con el error en la ilicitud (JAKOBS (2004) pp. 348 y ss.). 
al error de prohibición y su vencibilidad (art. $15^{39}$ ). Así, en principio, aplica una atenuante (muy calificada y obligatoria) cuando es vencible, pero si esa vencibilidad obedece a una suma indiferencia no procedería siquiera la atenuación. En este caso la regla es más dura que la alemana: la vencibilidad resulta inoperante para configurar una atenuante muy calificada en caso de suma indiferencia, imputándose así responsabilidad plena. La solución es más grave, pues ni siquiera habría posibilidad de atenuación. ${ }^{40}$ Semejante reconocimiento no sería tan gravoso si se dejara para excluir el error que a su vez impide afirmar la consciencia de ilicitud, ${ }^{41}$ luego de la prueba del dolo. Por ende, no existiría riesgo de presunción de dolo ni nociones amplias de dolo desde juicios de valor.

Detrás de las concepciones normativas, como ya observamos, puede advertirse la clara imposibilidad de inmiscuirse en la mente del agente. ${ }^{42}$ Dichas nociones también se apoyan en el rechazo a resabios de argumentos ad hominen, que supondrían mirar a la persona y no a su conducta. Los atisbos de un Derecho Penal de autor han de distinguirse y rechazarse. La conducta humana como base de un juicio de atribución no se identifica con la persona ni con sus características personales. ${ }^{43}$ Por otro lado, la base fáctica es distinta del juicio y de los criterios de imputación. Desde estas consideraciones se explican los esfuerzos dogmáticos, ya mencionados, en el sentido de concretar la previsibilidad en un deber de previsión, que funde de algún modo una norma de cuidado objetiva. De nuevo: ¿puede existir un deber de cuidado externo respecto un proceder que se desconoce?

La dificultad consiste en sostener la relevancia de normas que guían conductas frente a supuestos que no se representan. En este sentido, puede cuestionarse la delimitación de la mera previsibilidad desde un deber de previsión. ¿Cuándo existe un deber de previsión que explique la evitabilidad de la infracción de la norma por incumplimiento de un deber de cuidado? ¿Puede haber un deber de previsión respecto de supuestos inadvertidos?

A continuación, nos centraremos en la estructura subjetiva de esta clase de imprudencia, cuestionando su carácter inconsciente o sin representación alguna. Llegaremos a sostener que la atribución de un deber de previsión también exige cierto conocimiento.

\footnotetext{
39 Anteproyecto de Código Penal Chileno de 2018, Art. 15: "Error sobre la ilicitud del hecho. No es penalmente responsable quien actúa u omite desconociendo la ilicitud del hecho siempre que el error haya sido invencible para el hechor. En caso de ser vencible se reconocerá una atenuante muy calificada de conformidad con lo dispuesto en los artículos 60, 61 o 62, a menos que el error fuere indicativo de suma indiferencia acerca de la ilicitud del hecho".

${ }^{40}$ No habría atenuante muy calificada facultativa y, al no estar contemplada otra atenuante, sería difícil admitir una atenuante simple como se hace actualmente (sin regulación particular).

${ }^{41}$ ROJAS (2007), pp. 187-191, p. 190, refiere la evitabilidad del error a las dudas sobre la juridicidad de la conducta.

${ }^{42}$ Precisamente, el pasaje desde la concepción psicológica a la concepción normativa de la culpabilidad marcó el pasaje desde la cabeza del autor del hecho (comprobación de elementos subjetivos como hechos psíquicos) a la cabeza de quien tiene que juzgarlo (valoración según criterios valorativos).

${ }^{43}$ Claro, en este sentido, SOTOMAYOR (2016), pp. 694 y 695.
} 
VARGAS, Tatiana; PERIN, Andrea, "La "vidente" imputación imprudente. Peligrosidad de la conducta y consciencia del riesgo en la definición del dolo y la imprudencia".

\section{Aproximación a la delimitación de la imprudencia desde consideraciones tradicionales}

La definición de la imprudencia a partir del error (vencible o evitable) o de la "culposa ignorancia" explica la aceptación de una imprudencia inconsciente, en cuanto podía haberse conocido o al menos representado el tipo, y no se hizo. ${ }^{44} \mathrm{El}$ examen se centrará, como se expuso, en el conocimiento referido a los elementos del tipo penal, y no en la consciencia de ilicitud, cuestión de naturaleza distinta - aunque comparable- que concierne en cambio al juicio sobre la evitabilidad del error juris como elemento de la culpabilidad

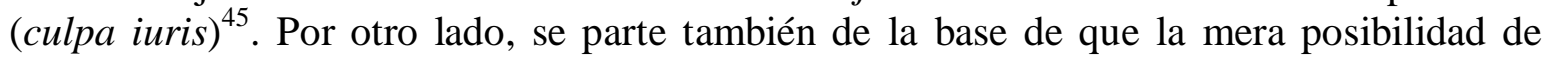
representación de la realización del tipo es débil y se puede restringir en términos de deber de previsión. ${ }^{46}$

En este sentido, el contexto médico es particularmente ilustrativo. Los procedimientos médicos generan diversos riesgos según su modalidad y son usuales los casos que exigen practicar exámenes para verificar o descartar determinado mal o afección, pues se conocen los peligros en general. Si se omiten tales exámenes evidentemente no se conocerán los peligros más concretos que enfrenta la conducta de atención y, por tanto, tampoco se emplearán los cuidados debidos. Sin embargo, la falta del examen que permitía conocer la peligrosidad concreta de la conducta no se basa en la total ignorancia respecto de las condiciones del caso. Así sucede en el caso de un médico que conoce los efectos generalmente adversos de un tratamiento o droga, por ejemplo, para los riñones o el corazón, que exigen practicar algunos exámenes para precisar conocimiento. Más evidente aún es el suministro de sustancias peligrosas (cuya peligrosidad es conocida) que exigen simplemente revisar si el caso supone riesgos concretos. Piénsese, por ejemplo, en el supuesto del anestesista que suministra dipirona (metamizol) sin leer la ficha clínica que registra una alergia del paciente ${ }^{47}$ sabiendo que la sustancia puede producir un shock anafiláctico y muerte a quienes son alérgicos.

Nino cita un caso similar: ${ }^{48}$ un médico prescribe una droga que sabe ser peligrosa para pacientes con problemas cardíacos, pero no realiza el examen para verificar tales riesgos cardíacos en el paciente. Lo mismo ocurre cuando se advierten ciertos estados, alteraciones

\footnotetext{
${ }^{44}$ Incluso en imprudencias conscientes el conocimiento del agente no se corresponde con la representación adecuada de los elementos del tipo, los que se representan como mera posibilidad. Esta representación inexacta es la que genera conflictos con el llamado dolo eventual, en cuanto parece ser un elemento común, que en realidad no es idéntico, según se planteará en este sucinto escrito.

${ }^{45}$ Sobre el paralelismo entre culpa(-imprudencia) y culpa iuris, y rechazando de esta forma -por coherencia sistemática- las doctrinas voluntaristas extremas (como la defendida por HALL (1963), passim), véase de nuevo el estudio comparado de FLETCHER (1971), pp. 420 y ss.

${ }^{46}$ Una exposición sobre la exigencia de deber de previsión en VARGAS (2017), pp. 354 y ss. En este sentido, destacan incluso legislaciones como la colombiana, que específicamente define la imprudencia sin previsión desde el deber de previsión: art. 23 Código Penal colombiano. "Culpa. La conducta es culposa cuando el resultado típico es producto de la infracción del deber objetivo de cuidado y el agente debió haberlo previsto por ser previsible, o habiéndolo previsto, confió en poder evitarlo". El problema es que podría identificarse la previsibilidad con el deber de previsión sin más atención que la sola posibilidad de conocer.

${ }^{47}$ Así, SCA de Santiago de 3 de marzo de 2008, Rol n ${ }^{\circ}$ 14193-2005.

${ }^{48}$ NINO (2006), p. 428.
} 
generales, que - por ello- requieren exámenes o derivaciones a otros centros o profesionales, como refleja la consideración que plantea la Corte Suprema ${ }^{49}$ frente a la descripción que hace el médico de "signos objetivos sugerentes y evidentes de una irritación química, sin advertir de una grave complicación en curso" y tomar "la conducta médica que correspondía, es decir, iniciar la heparinización y/o derivar de urgencia". La Corte toma en cuenta los síntomas conocidos para establecer el error (imputable) en el diagnóstico y la falta de tratamiento y/o derivación. ${ }^{50}$

Las conductas se estiman imprudentes por omitir exámenes debidos a partir del conocimiento de un riesgo para el paciente, aunque no suela advertirse; en este sentido, la Corte de Apelaciones de San Miguel ${ }^{51}$ expresa: "atendida la gravedad de las otras lesiones descritas, fractura con-minuta de maxilar y fractura nasal desplazada, justificaban por sí mismas la consulta en un centro de trauma y urgencia diferente". En realidad, la vinculación de conductas peligrosas conocidas para la determinación de mandatos de actuación no supone una novedad; al contrario, funda conductas omisivas, las que pueden ser dolosas o imprudentes precisamente con atención al nivel de peligrosidad del comportamiento respecto de la mayor o menor vinculación con la ejecución del hecho típico. Ciertamente, en ocasiones nuestros tribunales no son lo suficientemente claros. Así como mencionan exigencias de conocimiento, hablan también de imprevisión. ${ }^{52}$

Otro caso relevante destacado en otras oportunidades, ${ }^{53}$ aunque menos claro, es el que condena a una médico y una enfermera al suministrar Oncovin. La Corte de Apelaciones de Concepción, ${ }^{54}$ al imputar la culpa, señala que el resultado era previsible, destacando que la conducta de no verificar que el medicamento "correspondiera efectivamente a un procedimiento intratecal" fue descuidada, pues las imputadas "no han podido ignorar que el medicamento Oncovin solo procede por vía endovenosa". Se hace referencia así a una falta de cuidado "inexcusable" en la verificación de tal suministro, porque "bastaba que cualquiera de ellas, ante la más mínima duda, y dada la conocida peligrosidad de las drogas, leyera o hiciera leer las etiquetas para enterarse de la naturaleza de ellas". El elemento fundamental es entonces la admisión del conocimiento de la peligrosidad de las drogas, que exigía verificar el procedimiento de suministro.

\footnotetext{
${ }^{49}$ SCS de 10 de marzo de 2011, Rol n²285-2010.

50 “.... pese al dolor de la enferma y a los evidentes síntomas que presentaba, no efectuó el diagnóstico acertado y, por ende, el tratamiento y/o la derivación que correspondía, dándola de alta del establecimiento asistencial con una complicación médica en proceso de agravamiento, originada, precisamente, en la falta de cuidado de la aludida profesional, cuyo deber era el de poner a disposición de la paciente sus capacidades profesionales de acuerdo a un nivel general de prudencia, diligencia y pericia, es decir, guardando en su actuar una relación de semejanza con el proceder diligente de un profesional análogo".

${ }^{51}$ SCA de San Miguel de 16 de agosto de 2011, Rol n 240-2011.

${ }^{52}$ Por ejemplo, la SCS de 30 de enero de 2008, Rol n ${ }^{\circ} 6229-2006$, señala que el agente "no pudo menos que prever que estaba en sus manos evitar" y añade a continuación "hallándose dicha omisión o imprevisión en un nexo de causa a efecto con el resultado dañoso (considerando $14^{\circ}$ ). Sin embargo, luego precisa que "se trata de prestar al paciente los cuidados según los conocimientos adquiridos por la ciencia médica a la data del tratamiento" (considerando $15^{\circ}$ ).

${ }^{53}$ VARGAS (2017), p. 361; VARGAS (2010), pp. 119 y 120.

${ }^{54}$ SCA de Concepción de 23 de julio de 2008, Rol n $1326-2005$.
} 
En el caso indicado se plantearon dudas sobre la cantidad de drogas ${ }^{55} \mathrm{y}$, por tanto, el procedimiento empleado. La falta de verificación del contenido de medicamentos a suministrar cuando hay dudas supone cierto conocimiento o, al menos, una falta que ya no puede contar como "error". ${ }^{56}$ La Corte Suprema ${ }^{57}$ reafirma la consideración de "negligencia culpable" por "no adoptar el cuidado más elemental de verificar" el medicamento correspondiere a un procedimiento intratecal. Así, no solo confirma que los agentes no han "podido ignorar" que solo procede por vía endovenosa, sino que toma en cuenta para la entidad del descuido (inexcusable) las declaraciones de incerteza sobre el medicamento.

En otro ámbito, son interesantes las observaciones sobre la "indiferencia depravada" frente a conductas peligrosas conocidas, como la conducción de vehículos en estado de ebriedad, ${ }^{58}$ disparar a una multitud y poner bombas en lugares públicos. Se trata de conductas peligrosas conocidas, aunque las consecuencias para un específico sujeto se desconozcan. Esta indiferencia "depravada", "suma", "inexcusable" o "grave", no parece condecirse realmente con ignorancia. La indiferencia parece coincidir con una actitud basada en un cierto conocimiento antes que un mero desconocimiento, como destaca Duff ${ }^{59}$ precisamente al hablar de indiferencia desalmada o insensible (callous indifference).

Esto nos lleva a considerar el conocimiento latente de un riesgo general, ante una indiferencia práctica que tiene en cuenta el significado de la conducta. La distinción de conocimientos es relevante en el examen crítico de las tesis normativas extremas y requiere además tener en cuenta tanto distinciones entre juicio de valoración y objeto valorado, como la clase de objeto valorado: la conducta, su contexto y sus efectos. A este propósito, es probable que el carácter elemental de la distinción entre conducta ex ante y efectos ex post, al igual que el contexto del comportamiento y la modalidad de efectos, invite a que se pasen por alto. Ciertamente, cuando el agente actúa, su conocimiento se remite a ese

55 “... la enjuiciada C.B. expresó alguna duda en cuanto a la cantidad de jeringas preguntando 'y tantas', y luego de mezclarlas en una sola jeringa comentó 'no me calzan', queriendo significar que le sobraba medicamento, como lo señaló la testigo M.I.C.C., y lo admitieron las enjuiciadas, pero ni aquélla ni M.R. se preocuparon de verificar la naturaleza del contenido de las jeringas, limitándose esta última a manifestar, frente a las expresiones de la médico, que los medicamentos eran 'triasociados' y 'entonces dos en una".

${ }^{56}$ No solo es interesante la falta de confianza que supone la existencia de duda, sino tener en cuenta la noción de error que conlleva un "autoengaño", en términos de que para que exista error el agente ha de representarse como real un hecho que es contrario a la realidad; no se presenta como error. A este respecto, puede rescatarse algunos aportes sobre la estructura del error desde Sócrates con la distinción entre la "actitud proposicional" y el valor de verdad que se asigna a la proposición; ver VIGO (2013), pp. 9-37, pp. 15 y ss.

${ }^{57}$ SCS de 16 de junio de 2009, Rol n ${ }^{\circ}$ 5076-2008.

58 En este sentido, ver MATUS (2014), pp. 101-113, p. 104. También interesa el examen práctico de casos como el de Etcheberry a una SCA de Santiago de 1936 por un cerco electrificado en un gallinero que electrificó la reja de la casa vecina y mató a un niño que la abrió. Se evidencia la consciencia de un riesgo general, a diferencia de otro caso resuelto en 1957, donde la cerca electrificada del gallinero no alcanzaba ninguna otra reja vecina. No solo se advierte conocimiento de riesgos distintos (inexistente en un caso), sino que ambos casos suponen niveles de riesgo (objetivo) diferentes. ETCHEBERRY (1987), p. 257. También, VARGAS (2017), pp. 362 y 363.

${ }^{59}$ DUFF (1990), pp. 158 y ss. 
momento, es decir, ex ante. ${ }^{60}$ Sin embargo, el propio agente puede conocer las características de su conducta y sus alcances. Así, actúa con dolo de matar quien sabe, al momento de disparar contra otro, que su conducta crea un riesgo concreto contra la vida de la víctima (potencial) que seguramente o con bastante certeza será afectada. El dolo como conocimiento de la realización del tipo nunca es realmente cierto, pues los cursos causales no son controlables con totalidad. Y esto no obsta a que se pueda distinguir un conocimiento ex ante que se refiera a la conducta y advierta su nivel de riesgo, que en el caso expuesto se puede caracterizar por una peligrosidad concreta, en cuanto el objeto de la acción se conoce en el momento de la conducta de disparar. En ese momento ex ante el sujeto también puede representarse las consecuencias ex post de su actuar, el alcance de la persona cuya vida se expone. Desde esta perspectiva se puede admitir la representación al menos de un peligro concreto (ex post), que en caso de dolo directo parece bastante cercano a la lesión o, mejor, a la realización completa del tipo penal. ${ }^{61}$

Estas consideraciones y las que siguen respecto de la estructura subjetiva de la imprudencia inconsciente toman por base la distinción que plantea Hirsch ${ }^{62}$ entre peligrosidad, como características de la conducta ex ante con relación a las posibilidades de alcanzar el objeto protegido, y peligro, como estado ex post de amenaza a los bienes jurídicamente tutelados. El "error vencible" en que esencialmente estribaría esta imprudencia parece compartirse no solo con la imprudencia consciente y el dolo eventual, donde el conocimiento tampoco llega al nivel de certeza que supone el dolo directo. Nunca hay seguridad total en el conocimiento de cursos causales no completamente controlables. Así, la equivalencia parece alcanzar al dolo y, con ello, se vuelve a la amplitud subjetiva, aunque no desde pautas puramente normativas.

Sin embargo, se admite una diferencia objetiva: un error en la conducción de la conducta para la imprudencia y una conducción dirigida (no errada) para el dolo. La distinción se explica, en realidad, desde consideraciones subjetivas diferentes que parecen olvidarse, sea por una supuesta equivalencia fáctica, por una valorativa o por una separación evidente que se pasa por alto. La equiparación u olvido subjetivo genera cuestionamientos y confusiones entre categorías diversas, con graves repercusiones para la imposición de penas.

A continuación, nos centraremos en el nivel de conocimiento mínimo que puede legitimar el surgimiento y la atribución de exigencias normativas.

\section{El problema de la consciencia de peligrosidad y el conocimiento del peligro}

El conocimiento de la realización del tipo penal nunca es realmente cierto, ni siquiera en el dolo directo, tanto por el momento en que tiene lugar (ex ante), como por la falta de control

\footnotetext{
60 Se comparten las apreciaciones de FRISCH (2009), pp. 345-381, pp. 373, 378-381, respecto del conocimiento del agente en el momento en que realiza la conducta, sin que esto le impida proyectar sus consecuencias (futuras).

61 En este sentido, es especialmente interesante la distinción entre circunstancias de la acción y sus consecuencias que plantea DUFF (1990), pp. 40-44, en el examen de la intention, quien muestra además algunas de las dificultades que encierra la noción de acción y la importancia de especificar la "descripción de acción" (action-description) que se toma al distinguir circunstancias de consecuencias.

${ }^{62}$ HIRSCH (1996), pp. 509-529, pp. 513 y ss.
} 
VARGAS, Tatiana; PERIN, Andrea, "La "vidente" imputación imprudente. Peligrosidad de la conducta y consciencia del riesgo en la definición del dolo y la imprudencia".

total del agente ya advertido. Si se parte de esta base, es importante examinar el nivel de conocimiento del riesgo que importa la conducta de realización del tipo. Los niveles de conocimiento inciden en la aceptación — conformidad o indiferencia- del tipo o su rechazo por inexistencia de representación final.

Volvemos a la pregunta respecto de la delimitación de la imprudencia inconsciente mediante un deber de previsión. ¿Cuándo existe tal deber?, ¿se trata simplemente de la sola posibilidad de prever, de una explicación del deber de previsión a través de la previsibilidad? La cuestión que se plantea es si es viable y razonable establecer deberes de cuidado, aunque éstos se concreten en deberes de conocimientos, si las conductas no pueden ser guiadas por ellos.

Los deberes de conocimiento también han de tener una fuente, que no puede sino ser "vidente"; es decir, han de suponer una base consciente mínima. Se trata de ver como esta base, a su vez, se pueda desprender o deducir del grado de riesgo de la conducta. En efecto, el nivel de riesgo de la conducta que (objetivamente) alcanza a realizar el tipo penal se vincula con el conocimiento, como objeto de lo conocido. ${ }^{63}$ La relación no supone negar la prueba del conocimiento; simplemente, enfrenta las dificultades de toda prueba de consideraciones subjetivas, que se realiza en gran medida a partir de manifestaciones externas. $^{64}$

Sin perjuicio de que siempre puede predicarse un cierto grado de error en el conocimiento de los elementos del tipo penal, la clase de error (parcial) presente en la imprudencia explica la existencia de deberes objetivos de cuidado propios de esta estructura "subjetiva". Así, podría decirse que la diferencia con el dolo no estriba solo en el grado de conocimiento del riesgo, ${ }^{65}$ que supone también distintos niveles de error; existe una norma diferente que aparece en la estructura de la imprudencia, que no estaría en el dolo. La norma de conducta en casos dolosos - con conocimiento bastante cierto de la realización del tipo penal - se dirige directamente a la evitación del tipo; como no matar o salvar la vida en caso de

\footnotetext{
${ }^{63}$ KINDHÄUSER (2008), pp. 1-35, p. 5, advierte la relación del tipo subjetivo con el objetivo, en cuanto los elementos del primero están referidos a los del segundo. En similar sentido, DUFF (1990), p. 140, destaca que el carácter subjetivo de la conducta de un agente está determinado por su propio estado mental con relación a esa conducta. Este reconocimiento parte desde la crítica a la separación entre mente y cuerpo que caracteriza el dualismo clásico en el sistema angloamericano, según se subrayó al criticar la inferencia de lo subjetivo.

${ }^{64}$ Aquí se recuerda la relevancia del objeto de prueba, aun a pesar de su dificultad, al impedir presumir el dolo o quedarse a merced de una discrecionalidad judicial sin base, que torna en arbitrio.

${ }^{65}$ A propósito de la crítica a la teoría de la desviación esencial del curso causal para explicar la relevancia de la aberratio ictus, PUPPE (2017), pp. 807-809, advierte que solo es posible excluir el dolo y fundar la imprudencia si se exigen a la representación del autor sobre el curso causal y a la probabilidad de producción del resultado requisitos más elevados en caso de dolo que en conductas imprudentes; y que el curso causal no realizó el "peligro de dolo", sino un peligro parcial, que sería un "peligro de imprudencia". El dolo requiere la representación de un peligro cualificado y que este peligro mayor se haya realizado en el curso causal que lleva al resultado. En la representación de un "peligro de imprudencia" no se plantea al autor la cuestión de la aprobación o aceptación del (riesgo de) resultado. En contra, las tesis que postulan diferencia de grado; en Chile especialmente, VAN WEEZEL (2009), pp. 45 y ss.
} 


\section{Polít. Crim. Vol. 15, № 29 (Julio 2020), Art. 5, pp. 111-140 [http://politcrim.com/wp-content/uploads/2020/05/Vol15N29A5.pdf]}

homicidios. ${ }^{66}$ En cambio, en los supuestos imprudentes no se trata de dirigir prohibiciones de realización del hecho típico; se establece un cuidado necesario para evitarlo, que supone una norma de conducta distinta, un deber de evitación indirecta del tipo. ${ }^{67}$

El deber de cuidado surge frente a conductas peligrosas (al poderse realizar un tipo penal), siempre que sean conocidas. El desvalor subjetivo y objetivo de la conducta es menor. El riesgo es de menor intensidad, aunque efectivamente se realice en el resultado típico, al igual que una conducta dolosa. La peligrosidad de la conducta, como amenaza de realización del tipo ex ante, es menor en comportamientos imprudentes, a pesar de la producción del tipo por la interacción mayor de otros factores. El agente tiene un menor control respecto de su ejecución cuando el riesgo creado por la conducta, su peligrosidad, también es inferior. Este control importa un poder de evitación del tipo reducido, ${ }^{68}$ que solo puede existir si se conoce la peligrosidad de la conducta realizada. Aun este menor control tiene sentido respecto de procesos conocidos y no ciegos, que admiten dirigir una regla de cuidado en la conducción de la conducta para evitar el tipo penal. En ese sentido, se comprende también que la mera torpeza (aún consciente) no sea en general punible y, cuando lo es, no tenga la entidad de los comportamientos dolosos.

El conocimiento que supone el dolo funda la existencia de un mandato directo dirigido a evitar la realización de la conducta punible. Distinto es el conocimiento que hace surgir un deber de evitación indirecto por medio del cumplimiento del cuidado exigido. Desde esta perspectiva, se aborda la propuesta de precisión de la citada imprudencia inconsciente y su consecuente delimitación de otras modalidades subjetivas.

Volvemos a la pregunta sobre el error de tipo evitable, que determina esa clase de imprudencia. La evitabilidad o vencibilidad del error ha de fundarse, pero también hay que distinguir qué se desconoce en realidad. Está claro que el desconocimiento de aquello que es imposible de prever es inevitable. Este juicio de imposibilidad de conocer es complejo frente a la mera posibilidad de resultados, especialmente cuando se hace después de que se ha realizado objetivamente un tipo (aparentemente todo lo producido es conocible después). Por eso, la sola posibilidad no es suficiente. Ante el desconocimiento, hay que establecer si existía posibilidad real de conocer, fundada no en meras eventualidades. Destaca entonces la necesidad de revisar la evitabilidad del error y justificarla. Importa aclarar cuál es el objeto desconocido y, desde este punto de vista, interesa volver a distinguir peligrosidad de peligro.

Se parte de la base de que el juicio que recae sobre la determinación del conocimiento, si bien se realice ex post facto, siempre ha de remontarse al momento de realización de la

\footnotetext{
${ }^{66}$ La descripción típica del homicidio simple en el Código Penal chileno, como "el que mate a otro" (art. 391.2), admite tanto prohibiciones como mandatos.

${ }^{67}$ Cuando se refiere al dolo, JAKOBS (1997), p. 327, precisa que no basta con pensar en la mera posibilidad del resultado, pues solo un conocimiento que presente al autor como causante del resultado según "experiencia válida", puede tener efecto el "motivo de evitación directamente".

${ }^{68}$ SCHÜNEMANN (2002), pp. 105 y 106, habla de un mayor poder de evitación en conductas dolosas, de abuso de un poder de evitación cualificado y de un dominio. Como el dominio de los cursos causales nunca es total, aquí se prefiere hablar de mayor o menor control, no solo por ser más realista, sino porque permite distinguir mejor las diversas categorías subjetivas según la tesis propuesta.
} 


\section{VARGAS, Tatiana; PERIN, Andrea, "La "vidente" imputación imprudente. Peligrosidad de la conducta y consciencia del riesgo en la definición del dolo y la imprudencia".}

conducta. Esto significa que el objeto conocido es la conducta y sus propiedades en ese tiempo ex ante, pero no supone dejar de lado sus consecuencias porque tengan lugar ex post. Es posible proyectar las repercusiones de un comportamiento al realizarse y representarse efectos futuros, ${ }^{6}$ con mayor o menor certeza. De igual forma, la sola representación de las cualidades peligrosas de las conductas puede tener más o menos fuerza, según el propio nivel de peligrosidad de la conducta; sin perjuicio de que haya de probarse. Respecto del error evitable y la renombrada imprudencia inconsciente, no hay conocimiento actual de la realización del hecho típico, ${ }^{70}$ de su ejecución concreta. Desde esta perspectiva, se acepta aquí la falta de previsión, pero existe un conocimiento referido de algún modo al tipo, que es necesario delimitar para estar frente a una exigencia subjetiva mínima para efectos de imputación. Para ello es necesario distinguir entre la previsión y la previsibilidad (o riesgo) ex ante, junto con el objeto conocido y la entidad de dicho riesgo.

El examen normativo en la imprudencia, también en la "inconsciente", no debiera suponer una normativización que haga coincidir el objeto enjuiciado con el mismo juicio valorativo, de atribución, sin reconocer la conducta valorada. ${ }^{71}$ Ello, sin perjuicio de que la culpa o imprudencia sea tal luego del juicio de valoración. Lo que sucede es que el conocimiento se mantiene en el nivel de las propiedades o características peligrosas de la conducta y en el caso de la llamada culpa inconsciente falta toda representación de la realización ex post del tipo penal. Desde esta perspectiva, no existe previsión del tipo en términos de proyección ex post. En cambio, en el dolo (directo) se conoce además la realización ex post del tipo como una consecuencia bastante segura de la conducta. Sin embargo, cabe preguntarse qué distingue esta previsión de otras formas subjetivas. El problema de la confusión de categorías parece conservarse no solo entre el dolo eventual y la culpa o imprudencia consciente, sino también con el dolo directo.

\section{Una propuesta de estructura "vidente"}

Partiremos del conocido problema de delimitación entre dolo eventual e imprudencia consciente. En ambos supuestos, en la teoría, se admite la representación del resultado, así como se realiza ex post como consecuencia (material o jurídica) de la acción u omisión del autor, según el caso. Sin embargo, se trata de representaciones distintas respecto del

\footnotetext{
${ }^{69}$ En este sentido, son especialmente interesantes las advertencias de NIESE (1951), p. 43 respecto de la actualidad del conocimiento como categoría del "ser", que es o no es. Sin perjuicio de ello, lo posible es el efecto representado y no la representación en sí. El problema de la tesis de Niese es que señala que en la imprudencia la finalidad jurídico penal es irrelevante (p. 58).

70 DUFF (1990), pp. 160-162, distingue un conocimiento latente de un conocimiento actual precisamente en un caso de negligence -que suele considerarse irrelevante por faltar la consciencia de riesgo-, que concibe como supuesto de recklessness desde una noción de indiferencia práctica, que atiende al significado de la acción para ver el aspecto subjetivo. Afirma que allí el agente tiene un conocimiento latente del riesgo general que falla al aplicarlo al caso. Se opone en realidad, como hemos visto, a la exigencia de un estado mental explícito desde la creencia dualista que separa la mens rea del actus reus.

71 En este sentido, SCHÜNEMANN (2009), p. 339, habla de una normativización complementaria, que no desconoce la realidad social como base.
} 


\section{Polít. Crim. Vol. 15, № 29 (Julio 2020), Art. 5, pp. 111-140 [http://politcrim.com/wp-content/uploads/2020/05/Vol15N29A5.pdf]}

conocimiento de las propiedades peligrosas de la conducta, con atención al grado de peligrosidad real y objetivo. ${ }^{72}$

Normalmente, la consciencia de la peligrosidad concreta de la conducta se pasa por alto en el dolo directo frente a la previsión bastante certera de la producción ex post del tipo, probablemente por una especie de "auto-evidencia" acerca del nivel de peligrosidad efectivo de la conducta y el conocimiento que el agente tiene de ella. El grado de peligrosidad de la conducta realizada es tan alto que se llega a identificar con la previsión de la concreción del hecho típico. Se trata de una peligrosidad concreta y grave, de modo que el agente que conoce la conducta que realiza y sus propiedades no solo se representa tal nivel de peligrosidad, sino que además tiene consciencia de la producción del tipo. Así se explica, como decíamos, una norma de evitación directa de su ejecución.

Para el dolo eventual y la imprudencia consciente la "previsión" de realización del tipo es menos intensa y distinta en ambos casos. La pregunta por su distinción tiene sentido frente a este elemento de previsión que compartirían. Sin embargo, cabe cuestionar si se trata realmente de una misma previsión. El problema tiene más sentido si no se deja de lado la conducta que se realiza y se observa su nivel de riesgo ex ante y no solo ex post.

El peligro de concreción del tipo cambia según la peligrosidad de la conducta realizada. Aquí ya procede una diferencia estructural entre ambas categorías subjetivas, el dolo y la imprudencia, que explica la dirección de normas de conducta diversas: una norma de cuidado de evitación indirecta del tipo para la imprudencia y una norma de conducta de evitación directa del tipo para el dolo (aunque se llame eventual).

En caso de dolo eventual, el conocimiento de la peligrosidad concreta de la conducta no genera mayores dificultades, en cuanto se advierte ex ante un alto nivel (o una elevada probabilidad) de producción del hecho típico. ${ }^{73} \mathrm{El}$ grado de riesgo ex ante conocido y asumido es tan alto que mantiene una proyección de producción ex post alta, pero no tan cierta. En esta clase de dolo se pone énfasis en la "previsión" como consciencia y representación de un peligro concreto (que se realizaría ex post) ${ }^{74}$ y dicha previsión se basa en el conocimiento de la peligrosidad concreta, en la cercanía que supone la realización del tipo. Si bien esta cercanía no llega a niveles de certeza mayores, la representación de su

\footnotetext{
${ }^{72}$ También hay una distinción objetiva dada por el nivel de peligrosidad de la conducta: HASSEMER (1990), pp. 909-932, p. 917.

${ }^{73}$ ROXIN (2007), pp. 172 y 173, habla de una "peligrosidad tan grande" que solo puede ser entendida como realizada con dolo eventual. De todas formas, critica la tesis del "peligro de dolo", desde Puppe, por entender que solo toma en cuenta el criterio de reconocimiento de esta magnitud, que se valora por el juez. Sin embargo, no es una propuesta muy distinta de la idea de decisión, aunque no se advierta tal consideración. La consciencia de este nivel de riesgo y la realización de semejante conducta revela igualmente un elemento volitivo, independientemente de que requiera además una valoración normativa.

${ }^{74}$ KINDHÄUSER (2012), pp. 13 y 15, refiere este conocimiento del riesgo concreto al dolo. La remisión se explica como forma de dolo, por la falta de certeza y por la cercanía con la ejecución del hecho típico, aunque no distinga el dolo eventual. FEIJÓO (2001), pp. 262-265, aclara que ya hay dolo si existe representación de un peligro concreto. También en este sentido se comprende PUPPE (2002), pp. 314-316, aluda a un "peligro calificado" de que se produzca el resultado para el dolo eventual, aunque hable de peligro de dolo. Antes, PUPPE (1991), pp. 1-42. Se trata de la representación del hecho típico ex post como posible, con independencia de su valoración normativa.
} 
VARGAS, Tatiana; PERIN, Andrea, "La "vidente" imputación imprudente. Peligrosidad de la conducta y consciencia del riesgo en la definición del dolo y la imprudencia".

posibilidad específica justifica la dirección de una norma de conducta de evitación directa del tipo.

Los casos son bastante más complejos y difíciles de encuadrar en formas subjetivas, según expondremos al referirnos al más problemático, el de la imprudencia "inconsciente". Aquella consciencia (referida a la peligrosidad concreta) rescata algo propio de una modalidad de dolo y calza con una forma de "conocimiento" (knowledge) admitida como forma de mens rea en la tradición angloamericana, ${ }^{75}$ cuando el agente advierte las consecuencias de su conducta de modo cierto o "prácticamente cierto". 76

En cambio, en la culpa o imprudencia consciente, el nivel de peligrosidad de la conducta es menor; aunque se mantiene concreta en términos de realización posible del hecho típico. Los casos en realidad no son sencillos, pero puede señalarse que tienen en común la advertencia del hecho típico como posible ex ante. ${ }^{77}$ Se advierte una posibilidad mucho menor, que repercute en la previsión del resultado. Todavía puede hablarse de previsión, en cuanto se representan esas consecuencias como posibles, pero es distinta de la que define el dolo (aun eventual). El nivel de riesgo ex ante es más reducido, como en el caso de quien limpia un arma cargada, sabiendo que lo está, en un lugar con más personas, del caso de quien dispara al aire en ese mismo lugar. En ambos es posible dañar a otro, pero los distintos niveles de riesgo según el contexto de cada acción también repercuten en la representación de una consecuencia, así como se realizaría ex post. Aunque el conocimiento de la peligrosidad menor siga siendo concreta (respecto de la posibilidad del hecho típico y desde una perspectiva ex ante), por su entidad no se llega a advertir un peligro (tan)

${ }^{75}$ BRADY (1980), pp. 383, 390-391. Ver la definición del MPC $\S 2.02(2)$ (b). En nuestro medio, OXMAN (2013), pp. 161-163, argumenta que dicha forma de mens rea no sería equiparable con un dolo de segundo grado (nota 76), pues no obstante "el autor prevé el resultado como una posibilidad altamente probable o casi segura de sus actos, $(\ldots)$ no tiene verdaderamente en cuenta de un modo sincero si éste tendrá o no lugar". "El conocimiento únicamente se vincula a las circunstancias concretas que rodean la realización del hecho, respecto de las que es suficiente que el sujeto "acepte o asuma, sin tener serias dudas, en el momento del hecho, que las circunstancias que lo rodean están presentes"” (citando aquí a Simester, Spencer y Sullivan). Se advierte, en esto, cierta ambigüedad conceptual, confirmada por el análisis de STARK (2016), pp. 123 y ss., quien nos muestra que la doctrina angloamericana entiende la noción de knowledge de distintas maneras, por ejemplo, en términos de "virtual certainty", o bien, de "justified true belief".

${ }^{76}$ DUFF (1990), pp. 27, 33, 38-98, considera dos variantes o matices del sentido de intention: uno restrictivo, que se refiere a las conductas que se dirigen a producir el resultado intentado ("acting 'in order to' bring about the intended result"), y otro más amplio, que incluye la representación o previsión de consecuencias ciertas y quizá incluso las probables. En el primer caso, advierte la conexión de intención con actuar por una razón; actúa con la intención de producir el resultado si ese resultado forma parte de las razones para actuar. Es el paradigma de intención, intended agency. La previsión de efectos secundarios (foreseen side-effects) no son parte de las razones para actuar, aunque sean ciertos. No responde al paradigma, pero cabe dentro de una concepción más amplia de "agencia intencional" (intentional agency), siempre que se prevean esos efectos con certeza o, al menos, con alta probabilidad. Se restringe a la previsión de efectos secundarios relevantes para la acción si brindan razones contra ellos.

77 Se toman argumentos de NINO (2006), pp. 427-432, que distingue la imprudencia con atención al conocimiento de la peligrosidad concreta de la conducta, precisamente por advertir la posible realización del resultado. Entre estas imprudencias y las negligencias que no supondrían consciencia de riesgos, admite una clase de negligencias que se basan en el conocimiento de una peligrosidad genérica, que es la que se toma para desarrollar la propuesta de delimitación que se presenta aquí respecto de la llamada culpa inconsciente, en conjunto con otras consideraciones. 


\section{Polít. Crim. Vol. 15, № 29 (Julio 2020), Art. 5, pp. 111-140 [http://politcrim.com/wp-content/uploads/2020/05/Vol15N29A5.pdf]}

concreto de realización. Únicamente cabe representarse un peligro ex post más general o un peligro que podríamos definir abstracto, como estado de amenaza que se caracteriza por una situación de descontrol general, sin necesidad de un bien individual afectado ${ }^{78}$ En este sentido se puede hablar de una "previsión", pero de un peligro más general y no concreto, que explique el surgimiento de una norma de cuidado en la conducción para evitar (indirectamente) la realización del tipo penal.

Si bien la realidad es rica y los supuestos diversos, ${ }^{79}$ la distinción permite destacar los elementos propios de esta categoría subjetiva. Brady se ocupa de la complejidad de casos que pueden calificarse como recklessness, pero a la vez admite que todos suponen advertencia de riesgos ${ }^{80}$ Esta consciencia se vincula con la representación del peligro, de la realización de dichos riesgos ex post, que parece cambiar en cada supuesto. La delimitación que plantea se comprende mejor desde la propuesta que aquí se sostiene, al distinguir objetos de representación y clases de conocimiento.

Brady $^{81}$ separa ocho clases de recklessness, ordenados desde cierto elemento de entidad, aunque precisa que el primero es el más característico (y supuestamente el más grave). Se trata de quien advierte la naturaleza del riesgo y cree que las consecuencias son probables, atendida la naturaleza y probabilidad del riesgo, sin importar que las consecuencias ocurran de una u otra forma, e igualmente actúa. Puede distinguirse la advertencia del riesgo, referido a la conducta, de la consciencia de sus posibles consecuencias. De todas formas, esta previsión no comprende exigencias de certeza. Al contrario, contempla no solo la mera probabilidad de realización del hecho típico, sino también un elemento de indiferencia, que en la noción de Brady tiene que ver con la voluntad ${ }^{82}$ con que no importe demasiado las consecuencias de un actuar peligroso conocido por el agente. ${ }^{83}$

Así, este autor subraya otros tres casos en los que el agente advierte la naturaleza del riesgo y la probabilidad de las consecuencias, pero cambia la relación con estos efectos, que no dejan en todo caso de percibirse. El primero de este grupo es aquél en que el agente espera que las consecuencias no ocurran. Está considerando deseos, apreciaciones valorativas, irrelevantes respecto de la representación de la peligrosidad y del peligro en términos de decisión, de asumir los riesgos al actuar. En el tercer supuesto (el segundo de este grupo), el

\footnotetext{
${ }^{78}$ A pesar de que esta propuesta puede ser discutible, se trata de admitir situaciones de amenaza ex post reales, no presuntas, solo que no se identifica un bien protegido individual que entre en contacto directamente con la conducta peligrosa, como ocurre con el peligro concreto. Más sobre esta tesis que rechaza presunciones y propuestas estadísticas, VARGAS (2007), pp. 331 y ss.

${ }_{79}$ Piénsese en los supuestos de contagio de VIH, entre los más discutidos en el marco del debate doctrinario a propósito de la distinción entre culpa consciente y dolo eventual. Como es sabido, aun dependiendo del tipo de relación sexual, el riesgo de contagio es por lo general muy bajo. Entonces, preguntémonos: ¿Podría ese dato estadístico llevarnos a calificar de imprudente, y no dolosa, la conducta de quien, consciente de su estado de portador (VIH positivo), expone la pareja no portadora (VIH negativo) al riesgo de trasmisión, cuando dicho riesgo, objeto de una representación efectiva, finalmente se realice en el resultado de contagio?

${ }^{80}$ Reconoce que todos los casos de recklessness pueden convertirse en "exposición intencional al riesgo", BRADY (1996), p. 394.

${ }^{81}$ BRADY (1996), pp. 390-392.

${ }^{82}$ BRADY (1996), pp. 387-390.

${ }^{83}$ Esta "indiferencia" es el elemento lato sensu volitivo que, al fin y al cabo, caracteriza también a la denominada "segunda fórmula de Frank".
} 
agente conoce el riesgo y la posibilidad de las consecuencias, pero cree que esas consecuencias son poco probables. La hipótesis podría ser distinta si es que supone una representación de consecuencias menor, pero no si conoce el mismo nivel de probabilidad de realización del resultado. En tal caso la creencia es similar al deseo. De todas formas, se mantendría la consciencia de los posibles resultados, la previsión. El cuarto caso (tercer supuesto de este grupo) aúna el deseo de que no se produzcan consecuencias con la creencia de que su producción es poco probable. Aunque podría considerarse una vinculación subjetiva menor, si se tienen en cuenta los deseos, el agente no deja de representarse ex ante el riesgo de la conducta (idéntico) y de prever el hecho típico como posible.

Luego, Brady señala dos casos que parecen relacionarse con las categorías de culpa o imprudencia consciente e inconsciente en nuestro sistema. Este sentido se desprende a raíz del cuestionamiento que hace acerca de la mayor gravedad de una u otra con atención a la representación de las consecuencias ${ }^{84}:$ ¿Es más culpable un agente que es suficientemente cuidadoso para pensar en los riesgos y que decide actuar a pesar de los riesgos, o aquél que no se preocupa para nada por pensar en la realización del riesgo? La reflexión sobre la realización del riesgo alcanza la representación del resultado. De este modo, su inclusión en la primera alternativa, y no en la segunda, calza con lo que llamaríamos imprudencia consciente frente a otra que no lo sería. Sin embargo, al describir ambas opciones como formas de recklessness no queda tan claro qué considera y a qué modalidad responden. El primer caso del grupo que estamos considerando (el quinto de los que hemos indicado) sería aquel en que el agente advierte la naturaleza y probabilidad del riesgo y no se detiene a pensar antes de realizar la conducta. La consciencia de la peligrosidad concreta de la conducta no se pone en duda, el cuestionamiento está en la representación de las consecuencias, de la previsión del hecho típico. Cabe preguntarse si con ese nivel de conocimiento, del riesgo ex ante concreto de la conducta (naturaleza y probabilidad), nada conoce respecto de la posible realización del hecho típico.

No detenerse a pensar sobre la concreción del resultado niega la previsión de un peligro concreto, pero no necesariamente la de una posible realización ex post general suficiente para la imputación de una imprudencia "consciente". La asunción de este nivel de riesgo, que supone realizar una conducta conocida y concretamente peligrosa, alcanza la representación de un peligro ex post general.

Por otra parte, el supuesto siguiente (el segundo de este grupo, el sexto en general) comprende al agente que advierte la naturaleza y probabilidad del riesgo y piensa en él, pero decide erradamente que la conducta está justificada y la realiza. Ahora el sujeto no solo conoce la peligrosidad concreta de la conducta, sino que, al pensar en este riesgo, parece prever el resultado como posible. Sin embargo, la descripción no es tan clara. Al pensar en el nivel de riesgo y realizar igualmente la conducta, el agente estaría aparentemente conociendo la posibilidad del hecho típico y el error estaría en la ejecución descuidada, en una dirección sin el cuidado debido para evitar el tipo. En este sentido, sería

${ }^{84}$ BRADY (1996), p. 391. 


\section{Polít. Crim. Vol. 15, No 29 (Julio 2020), Art. 5, pp. 111-140 [http://politcrim.com/wp-content/uploads/2020/05/Vol15N29A5.pdf]}

un caso de culpa o imprudencia consciente. El ejemplo, en cambio, no vincula el error con la conducción ni con la representación del peligro, sino con apreciación de la justificación de la conducta. Entonces, el agente conoce la peligrosidad concreta de la conducta (naturaleza y probabilidad del riesgo) y prevé el hecho típico, pero el error parece dirigirse a la autorización de la conducta y no a su ejecución cuidadosa. La equivocación se referiría entonces a la licitud de la conducta, por lo que tendría otro sentido, con independencia de la discusión que puede generar el tratamiento sobre error de prohibición.

Finalmente, Brady menciona dos supuestos en los que, en realidad, el conocimiento de la peligrosidad concreta falla. Aunque no emplea estos términos, son los únicos casos en los que la advertencia del riesgo (ex ante) cambia y no solo la representación de las consecuencias de la conducta. Alude a situaciones que combinan casos de negligence ${ }^{85}$, referidos a falta de algún conocimiento, y de recklessness, que sí implicarían conocimiento. El primero de ellos (el séptimo en general) se refiere a quien solo advierte la naturaleza del riesgo y falla en captar su probabilidad. Nada dice sobre la representación de las consecuencias de la conducta, pues estas no parecen conocerse cuando el agente ni siquiera es consciente de la peligrosidad concreta de la conducta (naturaleza y probabilidad). El segundo y último caso (el octavo en general) alude al agente que advierte el riesgo, pero falla en percibir su naturaleza (gravedad). Solo se refiere a una consciencia de riesgo general — sin atender a naturaleza y probabilidad—, donde falta la previsión del resultado, como se aprecia en el ejemplo que cita Brady: el agente ve "algún" peligro para la persona, pero no advierte el riesgo de serio daño o muerte. Este último caso parece coincidir más con nuestra categoría de culpa o imprudencia inconsciente por la falta de previsión del resultado. Ciertamente, ambos supuestos pueden coincidir con esta forma de imprudencia desde que ninguno incluye tal previsión del hecho típico. Ellos pueden comprenderse dentro de una noción de "imprudencia consciente sin previsión", cuya legitimidad y relevancia aquí se quiere defender, y que puede explicar semejante combinación entre recklessness y negligence.

Para la llamada culpa o imprudencia inconsciente sigue teniendo sentido dirigir una norma de cuidado objetiva de evitación por la realización de una conducta peligrosa, aunque ya no concreta, sino general o abstracta ${ }^{86}$. La conducta objetivamente ha de generar un riesgo ex ante general, en cuanto puede realizar hechos típicos de alguna clase, y el sujeto que actúa ha de haber tenido consciencia de esa peligrosidad. Con este nivel de riesgo y de conocimiento, el agente no logra representarse un peligro ex post ni siquiera general o abstracto; por lo que desde este punto de vista no habría previsión (de resultado alguno).

\footnotetext{
${ }^{85}$ BRADY (1996), pp. 390 y 391.

${ }^{86}$ Con otro énfasis, se rescata la advertencia de FEIJÓO (2001), pp. 262-265. Si bien se refiere a la previsibilidad objetiva, alude al conocimiento de una "peligrosidad abstracta" para fundar la imprudencia. Así también se explica la consideración subjetiva en imprudencias inconscientes de SILVA (1994), pp. 41-58, p. 47, que ha de tener en cuenta siempre la mayor entidad del riesgo. Por otro lado, KINDHÄUSER (2012), p. 16, destaca que no todo error en el conocimiento exonera de responsabilidad. Lo admite no solo si era posible el conocimiento, sino también si "había derecho a esperar", y un motivo para evitar la conducta. El derecho a esperar el conocimiento se condice con la exigencia de un deber de conocer como contracara y que solo tiene sentido desde una conducta consciente.
} 
VARGAS, Tatiana; PERIN, Andrea, "La "vidente” imputación imprudente.

Esta clase de imprudencia ya no se delimita por la sola previsibilidad, como mera posibilidad de conocer; es decir, como mera imputación de conocimientos debidos en cuanto objetivamente exigibles. Aunque falta previsión, la previsibilidad se restringe por un deber de previsión, cuya existencia no es automática. Este deber de prever se puede imputar al agente si se da un paso más y se pone atención en el grado de peligrosidad de la conducta y el conocimiento que ha de tener el mismo, según el contexto, circunstancias y posibles efectos. En este sentido ha de entenderse la pregunta de Brady ${ }^{87}$ respecto de un deber de investigar del agente precisamente en el caso de que él advierte el riesgo general, no la naturaleza o gravedad ex ante. Se trata del último supuesto de recklessness -combinado con la negligence- que cita. Se pregunta si aquí, ¿no queremos decir que fue advertido y debe haber investigado la situación más profundamente?

Esta imprudencia no es ciega, pues el agente es consciente de la peligrosidad general de la conducta, y este nivel mínimo de conocimiento funda su deber de previsión; es decir, un deber de proyección del hecho típico, así como se realizaría ex post, al menos como peligro general (o como categoría de riesgo). El deber de previsión surge entonces de dicho conocimiento, legitimando la exigencia de cuidado en la conducción de la conducta para evitar la realización del tipo, de manera que la infracción de dicha exigencia justificaría una imputación de responsabilidad de forma equivalente a la imprudencia con previsión ${ }^{88}$.

\section{Consideraciones finales y síntesis}

La definición de consideraciones subjetivas de la conducta humana enfrente no solo dificultades probatorias, que evidentemente pasan por su relación con la manifestación externa de pensamientos y conocimientos. En este escrito se buscó particularmente poner atención a la modalidad subjetiva más compleja, tanto por sus nexos con determinaciones normativas, como por la dificultad de hallar realmente un elemento subjetivo que la defina. Así, se buscó indagar más en la culpa o imprudencia "inconsciente", haciendo referencia también a ciertos casos en el contexto médico. La elección no solo se explica por la frecuencia de conductas imprudentes frente a las dolosas. La actividad médica se muestra como un ámbito especialmente propicio para esas formas de imprudencia inconsciente, donde la previsibilidad del hecho típico se restringe por un deber de previsión que equipara esas imprudencias a los supuestos de imprudencia con previsión (la llamada consciente).

\footnotetext{
${ }^{87}$ BRADY (1980), p. 391.

${ }^{88}$ DUFF (1990), pp. 161 y ss., considera que casos de falta de advertencia del riesgo creado pueden reflejar el mismo tipo de "indiferencia práctica" que la consciente asunción de riesgos también manifiesta, pero sobre la base de distintos conocimientos. Admite que en los primeros supuestos de inadvertencia existe previsión de "algún riesgo" como efecto secundario de la conducta y falta advertencia del riesgo. No queda muy claro qué riesgos distingue, pero luego los separa. Habla de la existencia del "conocimiento latente" de un "riesgo general" que permitía al agente reconocer el riesgo para la víctima y de un fallo en aplicar el conocimiento. Parece referir este yerro a un conocimiento actual que falta y que puede calzar con la inadvertencia de una peligrosidad concreta como lo que aquí se propone, que según el contexto de la conducta debía advertir. El primer riesgo puede comprenderse en términos de peligrosidad general que se ha de conocer. Así se comprende que Duff mantenga el cargo por una "indiferencia desalmada" desde el conocimiento latente de un riesgo general, a partir del significado de la conducta.
} 


\section{Polít. Crim. Vol. 15, № 29 (Julio 2020), Art. 5, pp. 111-140 [http://politcrim.com/wp-content/uploads/2020/05/Vol15N29A5.pdf]}

En este escrito se cuestiona la referencia consciente e inconsciente que suele hacerse a la imprudencia, respecto de los objetos conocidos, su nivel de riesgo, la clase y entidad del conocimiento. A partir de la distinción entre peligrosidad y peligro, referidos a las propiedades de la conducta ex ante y a sus consecuencias ex post, se separan grados de peligrosidad y de peligro, general - $\mathrm{O}$ abstracto- y concreto. Estas características materiales, como objeto del conocimiento, también suponen formas de conocimiento diversas, que han de probarse. Desde la modalidad subjetiva más débil, se establecen distintas categorías que explican la dirección de diversas normas de conducta, sin confundir objeto de juicio con consideraciones normativas.

Se consideran así supuestos dolosos aquellos que suponen conocer el hecho típico como consecuencia prácticamente segura (dolo directo) o, al menos, con una alta probabilidad, de modo que suponga prever un peligro concreto (dolo eventual). Esta previsión pasa por el conocimiento de la peligrosidad concreta de la conducta, que, por evidente, suele desatenderse.

Las conductas imprudentes, en cambio, se refieren a una peligrosidad (ex ante) de menor entidad y a riesgos menos irrazonables. Cambia el objeto de conocimiento, este también es distinto.

La hipótesis que parece más grave de imprudencia es aquella en la que el nivel de peligrosidad se conserva como concreta y el agente advierte un riesgo concreto ex ante, la clase y probabilidad de peligro de realización del hecho típico. Sin embargo, la probabilidad es de una intensidad menor. Por ello, además de advertir la peligrosidad concreta, el agente solo se representa un riesgo abstracto de realización del hecho típico. Se trata de una previsión básica que explica la dirección de una norma de cuidado en la conducción de la conducta.

Por otro lado, puede todavía admitirse una clase de culpa o imprudencia en la que el agente no prevea el hecho típico (así como se realizaría ex post), pero sí implique un comportamiento peligroso y cuya peligrosidad más allá de lo permitido ha de conocerse ${ }^{89}$. En este caso, desde la perspectiva del agente, la peligrosidad de la conducta ya no es

\footnotetext{
${ }^{89}$ En este sentido, PERIN (2017), pp. 207-266, p. 249, cuyo planteamiento ha de entenderse “... en el sentido garantista de subir el límite inferior de lo 'penalmente relevante', excluyendo de la tipicidad imprudente inconsciente aquellas conductas que, aunque ofensivas, no resulten normativamente comparables con otras que, dada la efectiva (demostrada) existencia de una representación por parte del autor de un posible resultado lesivo, se encuentren ya por ello al borde del dolo eventual". En efecto: "La representación efectiva del resultado no indica necesariamente una forma más reprochable de imprudencia, ya que ciertas hipótesis de imprudencia inconsciente pueden resultar, según las circunstancias, comparativamente más graves de otras que se definan de imprudencia consciente" (p. 254). Por ello, aunque falte la representación actual del resultado, el "deber de previsión" y prevención se puede basar en conocimientos "(1) sin lugar a duda al alcance del tipo de agente y, además, (2) idóneos para proporcionar a quien hubiese podido y debido tenerlos la clara (aunque hipotética) representación de un perjuicio a bienes jurídicos protegidos" (p. 253, trad. nuestra). Confróntese, RAZ (2010), pp. 1-18, p. 14 y ss., quien admite la imputación de responsabilidad no solo cuando hay conocimiento efectivo, sino también cuando sería fácil saber (aunque dicho conocimiento se refiere a la existencia del deber de evitación, más que a circunstancias que permiten representarse las consecuencias de la conducta): “(...) if agents are responsible when they know of the duty they are also responsible if they could easily know about it".
} 


\section{VARGAS, Tatiana; PERIN, Andrea, "La "vidente" imputación imprudente. Peligrosidad de la conducta y consciencia del riesgo en la definición del dolo y la imprudencia".}

concreta, sino general. Quien actúa ha de conocer semejante peligrosidad; por lo que no se trata de un comportamiento ciego, aunque falte la previsión. La advertencia de este riesgo general ha de explicar un deber de indagar la clase y probabilidad concreta ex ante, que permita visualizar también la posibilidad general de realización del hecho típico que manifiesta una norma de cuidado en la conducción del agente. Se ha de sumar a aquel conocimiento un deber de previsión de la peligrosidad concreta que alcance un peligro general, como exigencia que funda la equivalencia entre las distintas clases de imprudencia $^{90}$. Pueden incluirse aquí casos en los que se realicen conductas concretamente peligrosas ex ante, pero el agente yerre en su representación, con un deber de advertencia más evidente y siempre desde una conducta consciente o vidente de al menos su peligrosidad general.

\footnotetext{
${ }^{90}$ Se justificaría así la oportunidad de renunciar a sancionar de forma más grave la imprudencia consciente, i.e., con representación del resultado. Por lo mismo, no parece adecuada la solución de eliminar la imprudencia inconsciente del ámbito de la punibilidad, siempre que, como hemos argumentado en este estudio, además de ser objetivamente grave, ésta descanse en un nivel mínimo de consciencia acerca de la peligrosidad de la conducta que justifique la imputación de un deber de previsión. Sobre este aspecto, PERIN (2017), p. 254.
} 


\section{Bibliografía}

BRADY, James (1996): “Conscious Negligence”, en: American Philosophical Quarterly (Vol. 33, n 3), pp. 325-335.

BRADY, James (1980): "Recklessness, negligence, indifference and awareness", en: The Modern Law Review (Vol. 43), pp. 381-399.

BUSTOS, Juan (1995): El delito culposo (Santiago: Editorial Jurídica de Chile).

CADOPPI, Alberto (1993): "Mens rea", en: Digesto delle discipline penalistiche (Vol. 7), , pp. 618-652.

CANCIO, Manuel, “¿Crisis del lado subjetivo del hecho?”, en CANCIO, Manuel, Estudios de Derecho penal, Colección de Ciencias Penales, Lima: Palestra, 2010, N $^{\circ}$ 2, pp. 153-179.

CORNACCHIA, Luigi (2004): Concorso di colpe e principio di responsabilità per fatto proprio (Torino: Giappichelli).

DONINI, Massimo (2014): "Il dolo eventuale: fatto-illecito e colpevolezza", en: Diritto penale contemporaneo - Rivista trimestrale $\left(\mathrm{n}^{\circ} 2\right)$, pp. 70-127.

DONNA, Edgardo A., "Breve síntesis del problema de la culpabilidad normativa", en: GOLDSCHMIDT, James, La concepción normativa de la culpabilidad, (Montevideo-Buenos Aires: B de F), pp. 11-50.

DUFF, Robin (1990): Antony, Intention, Agency and Criminal Liability. Philosophy of Action and the Criminal Law (Oxford: Basil Blackwell).

ETCHEBERRY, Alfredo (1987): El Derecho Penal en la jurisprudencia, $2^{\mathrm{a}}$ ed. (Santiago: Editorial Jurídica de Chile), t. I.

FEIJÓO, Bernardo (2001): Resultado lesivo e imprudencia (Barcelona: J. M. Bosch).

FLETCHER, George P. (1971): "The Theory of Criminal Negligence. A Comparative Analysis", en: University of Pennsylvania Law Review (Vol. 119, n 3), pp. 401438.

FORNASARI, Gabriele (1990): Il principio di inesigibilità nel diritto penale (Padova: Cedam),

FRISCH, Wolfgang (2009): "Lo fascinante, lo acertado y lo problemático de la teoría de la imputación objetiva del resultado" (trad. Marcelo Sancinetti), en: SANCINETTI, Marcelo (Comp.), Causalidad, riesgo e imputación (Buenos Aires: Hammurabi), pp. 345-381.

GAMBARO, Antonio y SACCO, Rodolfo (2008): Sistemi giuridici comparati (Torino: Utet).

HALL, Jerome (1963): "Negligent Behavior should be excluded from Penal Liability", en: Columbia Law Review (Vol. 63, n 4), pp. 632-644.

HART, H. L. A. (1968): Punishment and Responsibility. Essays in the Philosophy of Law (Oxford: Oxford University Press).

HASSEMER, Winfried (1990): "Los elementos característicos del dolo", (trad. María del Mar Díaz), en: Anuario de derecho penal y ciencias penales (Vol. 43, n 3), pp. 909932.

HIRSCH, Hans-Joachim (1996): "Peligro y peligrosidad" (trad. Esteban Sola), en: Anuario de derecho penal y ciencias penales (Vol. 49, $\left.\mathrm{n}^{\circ} 2\right)$, pp. 509-529.

JAKOBS, Günther (1997): Derecho penal. Parte general, 2a . ed., (trad. Joaquín Cuello y José Luis Serrano, Madrid: Marcial Pons). 
VARGAS, Tatiana; PERIN, Andrea, "La "vidente" imputación imprudente. imprudencia".

JAKOBS, Günther (2004): "Indiferencia como dolo", (trad. Carlos Pérez del Valle), en: ZUGALDÍA, José Miguel y LÓPEZ, Jacobo (Coords.), Dogmática y ley penal: libro homenaje a Enrique Bacigalupo (Madrid: Marcial Pons), pp. 345-358.

KINDHÄUSER, Urs (2008): "El tipo subjetivo en la construcción del delito" (trad. Juan Pablo Mañalich), en: InDret ( $\left.n^{\circ} 4\right)$, pp. 1-35.

KINDH ÄUSER, Urs (2012): “Acerca de la delimitación entre dolo e imprudencia" (trad. Orlando de la Vega), en: Revista Jurídica Mario Alario D’Filippo (Vol. 4), pp. 8-18.

LOVELESS, Janet (2016): Complete Criminal Law: Text, Cases and Materials, $5^{\mathrm{a}}$ ed., (Oxford: Oxford University Press).

MAÑALICH, Juan Pablo (2015): “La imprudencia como estructura de imputación”, en: Revista de Ciencias Penales (Vol. XLII, no 3), pp. 13-35.

MAÑALICH, Juan Pablo (2017): "La tentativa de delito como hecho punible. Una aproximación analítica", en: Revista Chilena de Derecho (Vol. 44, n 2), pp. 461493.

MATUS, Jean Pierre (2014): "Ley Emilia", en: Doctrina y Jurisprudencia Penal ( ${ }^{\circ}$ especial), pp. 101-113.

NIESE, Werner (1951): Finalität, Vorsatz und Fahrlässigkeit (Tübingen: Mohr), 1951.

NINO, Carlos (2006): Los límites de la responsabilidad penal (Buenos Aires: Astrea).

PÉREZ, Gabriel (2011): "El concepto de dolo en Derecho penal. Hacia un abandono definitivo de la idea de dolo como estado mental", en: Cuadernos de Derecho Penal $\left(\mathrm{n}^{\circ} 6\right)$, pp. 11-49.

PÉREZ, Mercedes (2017): "Prueba y subsunción en el dolo: una cuestión de garantías constitucionales", en: SILVA, Jesús; QUERALT JIMÉNEZ, Joan J.; CORCOY BIDASOLO, Mirentxu; CASTIÑEIRA PALOU, María Teresa(Coords.), Estudios de Derecho penal. Homenaje al profesor Santiago Mir Puig, (Montevideo - Buenos Aires: B de F), pp. 355-369.

PERIN, Andrea (2017): "La condotta lesiva colposa. Una prospettiva ricostruttiva", en: Política Criminal (Vol. 12, n 23), pp. 207-266.

PERIN, Andrea (2018): "La redefinición de la culpa (imprudencia) penal médica ante el fenómeno de la medicina defensiva. Bases desde una perspectiva comparada", en: Política Criminal (Vol. 13, n 26), pp. 858-903.

PERIN, Andrea (2019): "When Risk Management Systems 'Fail': On Criminal Negligence and the Limits of Scientists' Responsibility”, en: O'MATHÚNA, Dónal P y DE MIGUEL BERIAIN, Iñigo (Eds.), Ethics and Law for Chemical, Biological, Radiological, Nuclear \& Explosive (CBRNE) Crises (Cham: Springer Nature), pp. 211-225.

PUPPE, Ingeborg (1991): "Der Vorstellungsinhalt des dolus eventualis", en: Zeitschrift für die gesamte Strafrechtswissenschaft (Vol. 103), pp. 1-42.

PUPPE, Ingeborg (2002): Strafrecht. Allgemeiner Teil (Baden-Baden: Nomos).

PUPPE, Ingeborg (2017): "La imputación del resultado al dolo", en: SILVA, Jesús; QUERALT JIMÉNEZ, Joan J.; CORCOY BIDASOLO, Mirentxu; CASTIÑEIRA PALOU, María Teresa(coords.), Estudios de Derecho penal. Homenaje al profesor Santiago Mir Puig, (Montevideo - Buenos Aires: B de F), pp. 807-809.

OXMAN, Nicolás (2013): “Una aproximación al sistema de imputación subjetiva en el derecho penal anglosajón”, en: Ius et Praxis (Vol. 19, n 1), pp. 139-194. 
OXMAN, Nicolás (2014): "Bases de la culpabilidad en el sistema anglosajón de derecho penal”, en: DÍAZ CORTÉS, Lina Mariola y PÉREZ ÁLVAREZ, Fernando (Coords.), Moderno discurso penal y nuevas tecnologías (Salamanca: Universidad de Salamanca), pp. 341-356.

OXMAN, Nicolás (2016): Sistema de imputación subjetiva en Derecho penal: El modelo angloamericano (Valencia: Tirant lo Blanch).

RAGUÉS I VALLĖS, Ramón (1999): El dolo y su prueba en el proceso penal (Barcelona: Bosch).

RAGUÉS I VALLÈS, Ramón (2012): "De nuevo, el dolo eventual: un enfoque revolucionario para un tema clásico", en: InDret (n 3), pp. 1-12.

RAZ, Joseph (2010): "Responsibility and the Negligent Standard", en: Oxford Journal of Legal Studies (Vol. 30, n 1), pp. 1-18.

ROBINSON, Paul. H., (1993): "Should the Criminal Law Abandon the Actus Reus-Mens Rea Distinction?", en: SHUTE, Stephen; GARDNER, John y HORDER, Jeremy (Eds.), Criminal Law: Action, Value and Structure (Oxford: Clarendon Press), pp. 187-211.

ROJAS, Luis Emilio (2007): “Teoría del error en Alemania”, en: Revista Penal (n 20), pp. 187-191.

ROMEO CASABONA, Carlos María (2009): Sobre la estructura del dolo (Ciudad de México: Ed. Ubijus).

ROXIN, Claus (1997): Derecho penal. Parte general (trad. de la $2^{\mathrm{a}}$. ed. alemana y notas de Diego Luzón Peña; Miguel Díaz y García Conlledo y Javier de Vicente Remesal, Madrid: Thomson Reuters Civitas), t. I.

ROXIN, Claus (2007): "Acerca de la normativización del dolus eventualis y la doctrina del peligro de dolo" (Trad. Manuel Abanto), en: ROXIN, Claus, La teoría del delito en la discusión actual (Lima: Grijley), pp. 165-191.

SÁNCHEZ-OSTIZ, Pablo (2008): Imputación y teoría del delito. La doctrina kantiana de la imputación y su recepción en el pensamiento jurídico-penal contemporáneo (Montevideo-Buenos Aires: B de f).

SÁNCHEZ-OSTIZ, Pablo (2017): "Imputación e incumbencias en Derecho penal", en: Política Criminal (Vol. 12, no 24), pp. 1211-1227.

SAYRE, Francis B. (1932): “Mens Rea”, en: Harvard Law Review (Vol. 45, n 6), pp. 9741026.

SCHÜNEMANN, Bernd (2009): Obras (Santa Fe: Rubinzal-Culzoni Editores) t. I.

SCHÜNEMANN, Bernd (2002): "De un concepto filológico a un concepto tipológico de dolo" (trad. Maria Sacher), en: SCHÜNEMANN, Bernd, Temas actuales y permanentes del Derecho penal después del milenio (Madrid: Tecnos).

SILVA, Jesús María (1994): "Aspectos de la responsabilidad penal por imprudencia de médico anestesista. La perspectiva del Tribunal Supremo", en: Derecho y Salud, (Vol. 2), pp. 41-58.

SIMESTER, A.P.; SPENCER, John R.; STARK, Findlay; SULLIVAN, Graham y VIRGO, G.J., (2016): Simester and Sullivan's Criminal Law: Theory and Doctrine (OxfordPortland: Hart Publishing).

SMITH, Holly (1983): "Culpable Ignorance", en: The Philosophical Review (Vol. 92, n 4), pp. 543-571. 
VARGAS, Tatiana; PERIN, Andrea, "La "vidente" imputación imprudente. imprudencia".

SOTOMAYOR, Juan (2016): "Fundamento del dolo y ley penal: una aproximación crítica a las concepciones cognitivo/normativas del dolo, a propósito del caso colombiano", en: Política Criminal (Vol. 11, n $\left.{ }^{\circ} 22\right)$, pp. 675-703.

STARK, Findlay (2016): Culpable Carelessness. Recklessness and Negligence in the Criminal Law (New York: Cambridge University Press).

VAN WEEZEL, Alex (2009): Error y mero desconocimiento en Derecho penal, $2^{\mathrm{a}}$ ed., (Santiago, LegalPublishing).

VARGAS, Tatiana (2010): "La imprudencia médica. Algunos problemas de imputación de lo injusto penal", en: Revista de Derecho, Universidad Católica del Norte (Vol. 17, $\left.\mathrm{n}^{\circ} 2\right)$, pp. 99-132.

VARGAS, Tatiana (2017): “Algunos antecedentes sobre el complejo 'deber de previsión' médico", en: Revista de Derecho (vol. XXX, n 1), pp. 351-375.

VARGAS, Tatiana (2007): Delitos de peligro abstracto y resultado, en: The Global Law Collection (Pamplona: Thomson, Aranzadi).

VIGO, Alejandro (2013): "La conciencia errónea. De Sócrates a Tomás de Aquino", en: Signos Filosóficos (Vol. XV, n 19), pp. 9-37.

WELZEL, Hans (1949): Das deutsche Strafrecht in seinen Grundzügen, $2^{a}$ ed. (Berlin: De Gruyter).

WELZEL, Hans (1961): Fahrlässigkeit und Verkehrsdelikte. Zur Dogmatik der fahrlässigen Delikte (Karlsruhe: Müller).

WELZEL, Hans (1997): Derecho penal alemán, 11ª ed. (trad. Juan Bustos y Sergio Yáñez, Santiago, Editorial Jurídica de Chile).

WINSLADE, William (1972): "Brady on Recklessness", en: Analysis (Vol. 33), pp. 31-32.

WILLIAMS, Pr. (1982): “A reply to Mr. Duff”, en: Cambridge Law Journal (Vol. 41, n 2), pp. 286-289.

ZIMMERMAN, Michael J. (1986): "Negligence and Moral Responsibility", en: Noûs (Vol. 20, n 2$)$, pp. 199-218. 